\section{DE LA MITIGACIÓN DE DESASTRES A LA INTERRUPCIÓN DE TRAMPAS DE RIESGO: LA EXPERIENCIA DE APRENDIZAJE- ACCIÓN DE CLIMA SIN RIESGO}

Adriana Allen $^{1, *}$, Teresa Belkow², Carlos Escalante Estrada 3 , Silvia de los Ríos ${ }^{4}$,

Marco Kamiya ${ }^{5}$, Rita Lambert ${ }^{1}$, Liliana Miranda ${ }^{6}$, Julia Wesely ${ }^{1}$ y Linda Zilbert Soto ${ }^{7}$.

\section{RESUMEN}

En las últimas décadas hemos asistido a una profunda reformulación de cómo entender las condiciones de riesgo en el contexto urbano. Sin embargo, aún enfrentamos significativos desafíos para capturar conceptual, metodológica y empíricamente los círculos viciosos de reproducción de riesgos que configuran 'trampas de riesgo urbano' frecuentemente invisibilizadas. Entendemos a las trampas de riesgo como el resultado de la reproducción de riesgos cotidianos y de desastres repetitivos y frecuentes de pequeña escala, que afectan en forma desproporcional a los sectores empobrecidos en forma altamente localizada. A partir de cLIMA sin Riesgo - un proyecto de investigación-acción desarrollado por los autores en el contexto de Lima - este artículo explora las condiciones que producen y reproducen estas trampas, cómo y dónde se materializan, quiénes son afectados y con qué consecuencias para aquellos que viven en barrios tugurizados y/o asentamientos informales y marginalizados. La discusión examina cómo el conocimiento espacial de la urbanización en riesgo y la evaluación critica de las inversiones y los esfuerzos de mitigación realizados por parte de pobladores y agencias estatales permiten avanzar hacia una apreciación más precisa del impacto de dichas trampas a lo largo del tiempo, así como hacia estrategias de acción para su interrupción.

\section{PALABRAS CLAVE}

Ciclos de acumulación de riesgo, trampas de riesgo urbano, capacidad de acción, gestión de riesgo de desastres, Lima

\section{ABSTRACT}

The last decades have witnessed a profound change in our understanding of the conditions of risk in urban contexts. However, we still face significant conceptual, methodological and empirical challenges in capturing the vicious cycles of risk accumulation that often render so-called 'urban risk traps' invisible. We define risk traps as the result of the reproduction of everyday risks and frequent small-scale disasters, which have highly localized impacts and disproportionately affect impoverished inhabitants. Based on the action-research project CLIMA without Risk (cLIMA sin riesgo), which was conducted by the authors in the context of two marginalized areas in the centre and periphery of Lima, Peru, this article explores the conditions that produce and reproduce these risk traps and it analyses how and where they materialize, who they affect and with what consequences. The discussion examines how spatial knowledge of urbanization at risk together with a critical evaluation of inhabitants' and state agencies' investments in mitigation efforts allows us to move towards a more accurate assessment of the impact of these risk traps over time, which is required for developing transformative strategies to disrupt them.

\section{KEYWORDS}

Risk accumulation cycles, urban risk traps, capacity for action, disaster risk management, Lima
1. The Bartlett Development Planning Unit, University College London, Londres, Reino Unido.

2. Consultora Independiente, Lima, Perú.

\section{CENCA Instituto de Desarrollo Urbano, Lima, Perú.}

4. Centro de Investigación, Documentación y Asesoría Poblacional (CIDAP), Lima, Perú.

5. Departamento de Economía y Finanzas Urbanas en ONU-HABITAT, Nairobi, Kenia.

6. Foro Ciudades para la Vida, Lima, Perú.

7. Experta independiente asociada con la Oficina de Prevención y Recuperación de Crisis del Programa de las Naciones Unidas para el Desarrollo, Lima, Perú.

*Autor de correspondencia: a.allen@ucl.ac.uk

\section{RECIBIDO}

31 de enero de 2017

\section{ACEPTADO}

20 de febrero de 2017

\section{PUBLICADO}

15 de julio 2017

\section{Formato cita}

Recomendada (APA): Allen, A., Belkow, T., Escalante Estrada, C., de los Ríos, S., Kamiya, M., Miranda, L., Wesely, J. \& Zilbert Soto, L. (2017). De la mitigación de desastres a la interrupción de trampas de riesgo: La experiencia de aprendizaje-acción de cLIMA sin Riesgo. REDER, 1(1), pp.6-28.

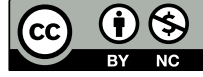

Todos los artículos publicados en REDER siguen una política de Acceso Abierto y se respaldan en una Licencia CreativeCommons Atribución-NoComercial 4.0 Internacional.

Revista de Estudios Latinoamericanos sobre Reducción del Riesgo de Desastres (REDER)

Diseño: Lupe Bezzina Tipografía: Hospital 


\section{INTRODUCCIÓN}

En las últimas décadas, la dinámica del desarrollo urbano en metrópolis como Lima se ha caracterizado por el crecimiento espontáneo y poco articulado sobre el territorio y sus ecosistemas, priorizando la captura privada de plusvalía y amenazando el derecho a la ciudad de los sectores más desfavorecidos. Este proceso es agudizado por la reproducción de 'trampas de riesgo', o círculos viciosos de acumulación de riesgos cotidianos y desastres episódicos de menor escala que imponen severos impactos en la vida diaria, medios de vida y bienes de la población en situación de pobreza, así como en el futuro ambiental y socio-económico de la ciudad.

Sin embargo, tanto la generación como los impactos de estas trampas de riesgo urbano reciben aún escasa atención en la formulación de políticas y programas públicos asociados a la gestión del riesgo de desastres. Este déficit incrementa aún más la vulnerabilidad de la población más desfavorecida y erosiona cotidianamente sus medios de vida, generando significativos costos e impactos para la ciudad y sus habitantes.

Trabajando con comunidades locales en el centro histórico (Barrios Altos) y en la periferia de Lima Metropolitana (José Carlos Mariátegui), el proyecto de investigación-acción cLIMA sin Riesgo' ha abordado esta problemática, generando nuevas metodologías para mejorar el conocimiento espacial y evaluar críticamente el impacto de las inversiones y esfuerzos realizados para mitigar riesgos por el Estado y las poblaciones locales a lo largo del tiempo. El conocimiento empírico, conceptual y metodológico producido aspira a contribuir hacia una planificación resiliente al cambio climático ${ }^{2}$ y al co-diseño de mecanismos de financiamiento y acción innovadores que sirvan como precedentes hacia un desarrollo urbano más justo en Lima, así como en otras ciudades de América Latina.

\section{¿RIESGOS COTIDIANOS O COTIDIANEIDAD DE LOS RIESGOS?}

El riesgo es comúnmente definido como la probabilidad de consecuencias negativas o pérdidas inducidas por la combinación de amenazas - naturales, socio-naturales o producidas por el ser humano- y condiciones de vulnerabilidad contrarrestadas por la capacidad para enfrentar y adaptarse a dichos riesgos (UNISDR, 2009; Wisner, Blaikie \& Cannon, 2004). Los desastres son simplemente la materialización de riesgos existentes y se expresan en daños y pérdidas concretas que exceden las capacidades existentes de mitigación.

Los riesgos están intrínsecamente conectados a procesos territoriales, sociales, ambientales y de planificación (o su falta o inadecuación) a través del desarrollo histórico de una ciudad y se conjugan a través de diferentes tipos de amenazas (CRID, 2008). Dichas amenazas incluyen desde la probabilidad de ocurrencia de fenómenos de impacto a gran escala tales como terremotos y tsunamis, hasta fenómenos de impacto altamente localizado como inundaciones, huaycos o deslizamientos de tierras provocados por el arrojo diario de aguas servidas en laderas en pendiente debido a la falta de infraestructura de desagüe; incluyendo también la probabilidad de accidentes por caídas en la ladera, o de enfermedades por la falta de salubridad o condiciones precarias de habitabilidad (Zilbert Soto, 2008).

En debates sobre el riesgo de desastres, los términos episódico, frecuente, cotidianos, extensivos, de escala menor, pero también pequeño y diario, son generalmente usados de manera indistinta, para describir condiciones de riesgo que contrastan del riesgo de desastres a gran escala. El riesgo cotidiano se define como "el conjunto de condiciones sociales de vida de la población que a la vez constituyen facetas o características (aunque no exclusivas) de la pobreza, el subdesarrollo, y la inseguridad humana estructural y limitan o ponen en peligro el desarrollo humano sostenible." (Lavell et al., 2003, p.70). Por su parte, la Oficina de las Naciones Unidas para la Reducción de Riesgo de Desastres describe los riesgos extensivos como la "exposición de poblaciones dispersas a amenazas reiteradas de baja o moderada intensidad y altamente localizada lo cual conduce a debilitar los impactos acumulativos de los desastres teniendo además relación con la pobreza, la urbanización y la degradación ambiental." (UNISDR, 2009, p.31)

En los últimos 20 años se registra un aumento significativo de reportes sobre desastres extensivos y sus impactos, ya sea en referencia a pérdidas relacionadas a viviendas dañadas, personas afectadas o daños a equipamiento de salud y educación, así como una tendencia creciente en la mortalidad, morbilidad y en las pérdidas económicas asociadas a estos riesgos extensivos, a lo largo del denominado 'sur global' (UNISDR, 2011). Esto ha llevado a una reconsideración del tipo de procesos que se conjugan en lo que se denomina 'espectro continuo del riesgo urbano' y que abarca fenómenos de diferente frecuencia, escala e impacto (Figura 1).
1. cLIMA sin Riesgo (http:// www. climasinriesgo.net) es un proyecto de investigación desarrollado gracias al apoyo de la Alianza Clima y Desarrollo (CDKN). CDKN es un programa financiado por el Departamento para el Desarrollo Internacional del Reino Unido (DFID) y la Dirección General de Cooperación Internacional (DGIS) de los Países Bajos en beneficio de los países en desarrollo. Las opiniones expresadas y la información incluida en el mismo no reflejan necesariamente los puntos de vista o no son las aprobadas por el DFID, la DGIS o las entidades encargadas de la gestión de la Alianza Clima y Desarrollo, quienes no podrán hacerse responsables de dichas opiniones o información o por la confianza depositada en ellas.

2. Las amenazas derivadas del cambio climático en Perú están asociadas al incremento de frecuencia, intensidad, duración y cambio en el calendario de ocurrencia de eventos climáticos extremos y eventos como inundaciones, sequias, huaycos, y aluviones vinculados entre otros, a los fenómenos El Niño La Niña (ENSO). 


\begin{tabular}{|c|c|c|c|}
\hline Naturaleza del evento & $\begin{array}{l}\text { Desastres de } \\
\text { gran escala }\end{array}$ & $\begin{array}{l}\text { Desastres de } \\
\text { escala menor }\end{array}$ & $\begin{array}{l}\text { Pérdidas ocasionadas } \\
\text { por riesgos cotidianos }\end{array}$ \\
\hline Frecuencia & $\begin{array}{l}\text { Generalmente } \\
\text { poco frecuente }\end{array}$ & $\begin{array}{l}\text { Frecuente } \\
\text { (regularmente estacional) }\end{array}$ & Cada día \\
\hline Escala & $\begin{array}{l}\text { Mayor, o potencial a } \\
\text { ser mayor (ej. } 10 \text { o más } \\
\text { muertos, } 100 \text { o más seria- } \\
\text { mente heridos, necesidad } \\
\text { de asistencia externa) }\end{array}$ & $\begin{array}{l}\text { 3-9 personas muertas, } \\
10 \text { o más heridos }\end{array}$ & $\begin{array}{l}\text { 1-2 personas muertas, } \\
1-9 \text { heridos }\end{array}$ \\
\hline Impacto total & $\begin{array}{l}\text { Puede ser catastrófico la } \\
\text { mayoría de veces y ocurre } \\
\text { particularmente en nacio- } \\
\text { nes de bajos y medianos } \\
\text { ingresos. Generalmente } \\
\text { contribuye a muerte pre- } \\
\text { matura y lesiones graves }\end{array}$ & $\begin{array}{l}\text { Probablemente una } \\
\text { contribución significati- } \\
\text { va y considerablemente } \\
\text { subestimada a muerte } \\
\text { prematura y enfermedad } \\
\text { grave o lesión }\end{array}$ & $\begin{array}{l}\text { En la mayoría de áreas } \\
\text { urbanas en África, esto } \\
\text { significa la principal cau- } \\
\text { sa de muerte prematura } \\
\text { y heridas de gravedad }\end{array}$ \\
\hline $\begin{array}{l}\text { Marco integral de } \\
\text { aproximación al riesgo, } \\
\text { incluyendo desastres de } \\
\text { gran y menor escala y } \\
\text { amenazas diarias }\end{array}$ & $\begin{array}{l}\text { Gran impacto para } \\
\text { la ciudad } \\
\text { Baja frecuencia }\end{array}$ & NTÍNUO DEL RIESGO & $\begin{array}{l}\text { Impactos de pequeña } \\
\text { escala para la ciudad } \\
\text { Muy alta frecuencia }\end{array}$ \\
\hline
\end{tabular}

Figura 1: Espectro continuo del riesgo urbano: Desastres de gran escala, de escala menor e impactos negativos por riesgos cotidianos en áreas urbanas.

Fuente: Bull-Kamanga et al. (2003).

Los riesgos cotidianos y episódicos ilustrados en la Figura 2, no sólo contrastan con eventos intensivos en cuanto a su escala e impacto, sino que su consideración permite reconocer las luchas y experiencias diarias de los hombres y mujeres, niños y niñas expuestos a procesos de urbanización y cambio urbano en riesgo. Los límites entre influencias humanas y naturales se hacen menos evidentes en estos casos, especialmente cuando se los analiza a lo largo de diferentes escalas temporales y espaciales y en relación a las prácticas cotidianas de construcción y gestión del hábitat. En Lima Metropolitana, como en otras ciudades del sur global, los riesgos cotidianos y episódicos exacerban los desafíos enfrentados por los sectores populares típicamente marginados, quienes frecuentemente quedan atrapados en trampas de riesgo.

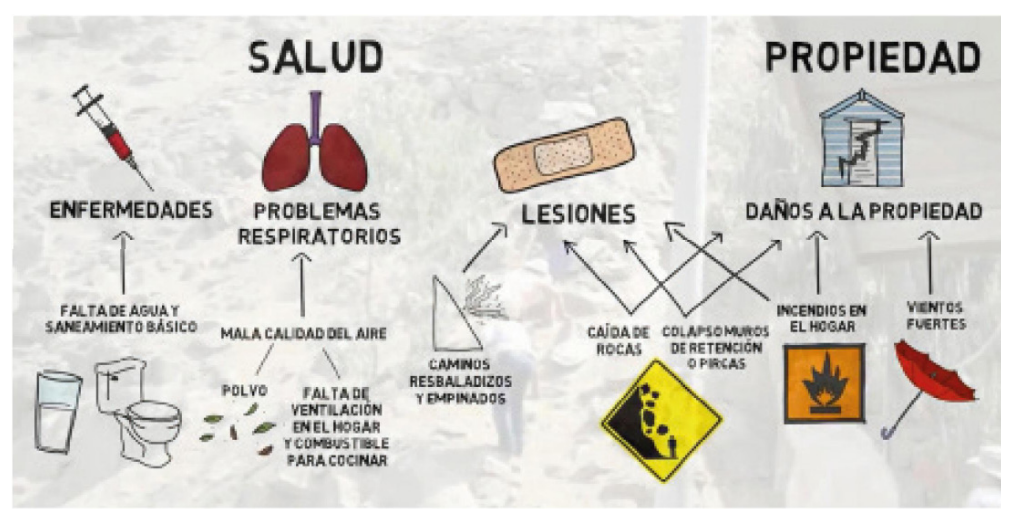

Figura 2: Riesgos cotidianos y episódicos frecuentes en la periferia de Lima. Fuente: Ahmed et al. (2015). 
El escaso reconocimiento de estos riesgos contribuye a hacerlos cada vez más invisibles, profundizando su internalización por parte de los hogares más vulnerables y limitando el diseño e implementación de intervenciones públicas preventivas. Entre los esfuerzos más destacados dirigidos a registrar y visibilizar desastres de escala menor y medir sus causas y consecuencias, figura el Sistema de Inventario de Desastres - DesInventar ${ }^{3}$, desarrollado por la Red de Estudios Sociales en Prevención de Desastres en América Latina (LA RED). En base a la información recopilada por este sistema, la Figura 3 muestra que en Lima Metropolitana, los desastres extensivos más comunes entre 1970 y el 2011 estuvieron relacionados a incendios, contaminación, colapso de estructuras, inundaciones y deslizamientos, siendo las zonas más afectadas el centro de Lima, donde el distrito del Cercado de Lima concentra el 19\% de los eventos registrados en toda la ciudad. Sin embargo, la mayoría de los desastres extensivos que ocurren en la periferia aún no son captados por este sistema, permaneciendo invisibles al conjunto de la sociedad (Allen et al., 2015).

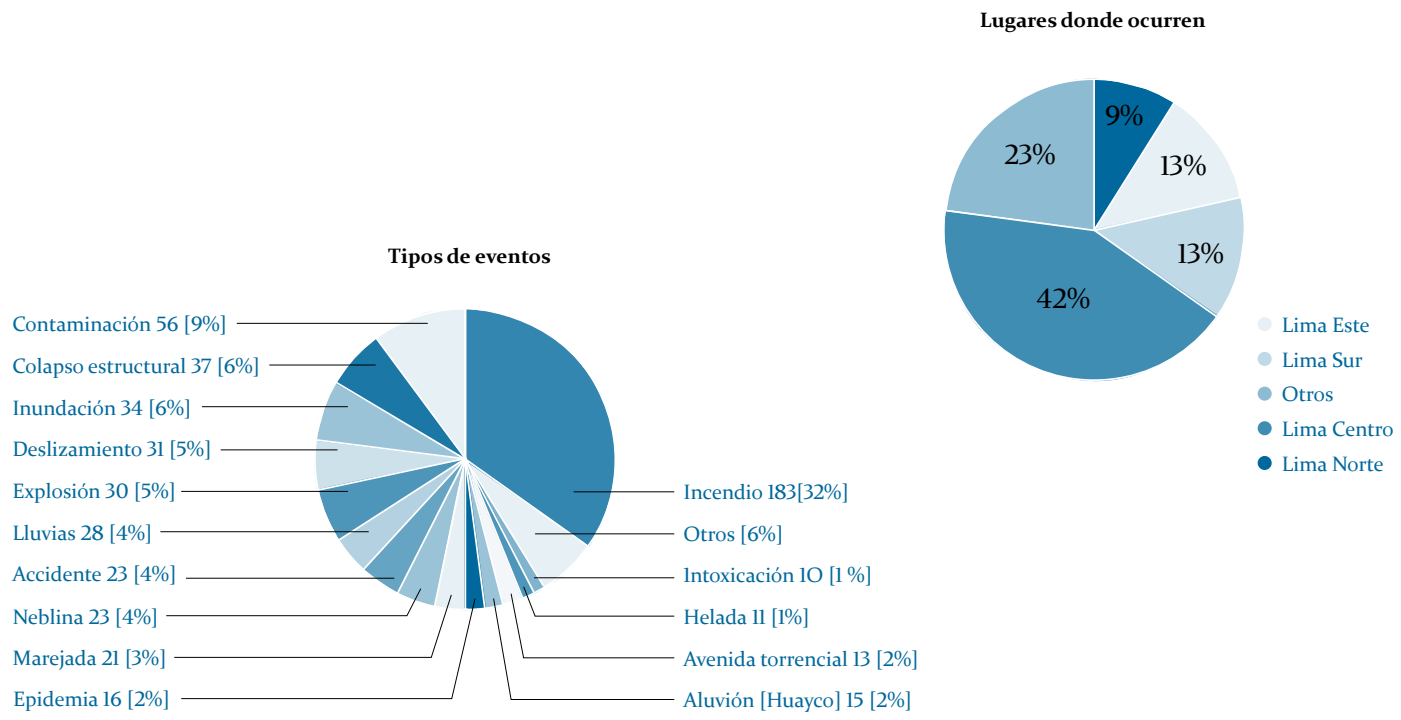

Figura 3: Localización y tipo de eventos de desastre más comunes en Lima Metropolitana.

Fuente: Allen et al. (2015), elaboración en base a DesInventar [www.desinventar.net].

Como fue señalado en la introducción, las trampas de riesgo resultan de la articulación y reproducción a lo largo del tiempo de condiciones de vulnerabilidad y amenazas diarias y episódicas - incluyendo desastres de menor escala - que afectan en forma desproporcional a los sectores sociales empobrecidos. Estas trampas son frecuentemente invisibles en el proceso de gestión y planificación del territorio urbano y su desarrollo debido en gran medida a una valoración errónea o incompleta del riesgo que predomina en las agencias estatales a cargo de la gestión del riesgo de desastres, tanto en Perú como en muchos otros países (UNISDR, 2015).

A nivel nacional, fuentes oficiales estiman pérdidas anuales de 73 millones de dólares a causa de la ocurrencia de desastres, solo entre los años 2006 al 2010 se reportaron más de 22 mil emergencias que afectaron a más de 6 millones de habitantes, ocasionando cuantiosos daños y pérdidas en vivienda, infraestructura y agricultura. En el ejercicio de valorizar el riesgo, se considera fundamentalmente lo que son las inversiones o proyecciones de inversión en medidas u obras de control, desarrollo de estudios e investigaciones o implementación de programas de capacitación y a veces el costo de acciones orientadas a mejorar la capacidad de respuesta y atención a emergencias por desastres. Sin embargo, valorizar el riesgo requiere no sólo la consideración de los mecanismos o acciones conducentes a paliar el problema sino también de las inversiones que paradójicamente generan condiciones de urbanización en riesgo.

Esto significa valorizar aquellos aspectos que han contribuido o conducido a la configuración de los riesgos que, luego se tratan de amenorar a través de medidas reactivas de mitigación que demandan mucha mayor inversión por la acumulación de efectos negativos a través del tiempo. Por ejemplo, la ocupación del cauce de un río, una quebrada o ladera demanda un conjunto de inversiones considerables para habilitar dicho terreno (primera suma de inversiones), mientras que frecuentemente se generan en forma simultánea condiciones de riesgo. Luego, con la finalidad de

3. Sistema de registro y consulta que permite observar la ocurrencia de desastres desde una escala espacial local, así como una herramienta conceptual y metodológica para la construcción de bases de datos de pérdidas, daños o efectos ocasionados por emergencias o desastres. Se alimenta de información recolectada a través de medios de comunicación y reportes institucionales. 
proteger lo edificado, se construye un muro llamado (o más bien mal llamado) medida de prevención (segunda inversión), que a la vez genera problemas o incrementa riesgos a poblaciones asentadas aguas abajo o quebrada abajo. Este proceso resulta en la probabilidad (riesgo) o el hecho (desastre) de que poblaciones se vean afectadas y deban invertir en la construcción de más obras de defensa y con mayores refuerzos (tercera suma de inversiones) y/o en su recuperación (cuarta suma de inversiones) lo cual simultáneamente aumenta su vulnerabilidad y erosiona su capacidad de acción (Allen et al., 2016)

Al valorizar el riesgo lo que se ha hecho es partir de la simple contabilidad del gasto o inversión en los muros de protección, sin dimensionar el escenario real de las inversiones que convergen en configurar y luego paliar el riesgo (total de la suma de inversiones). Lo que denominamos una 'evaluación errónea del riesgo', no examina las causas y/o procesos causales del riesgo sino que sólo ofrece una mirada parcial y superficial de sus efectos.

Otro ejemplo en la periferia de Lima es la construcción masiva de escaleras en los asentamientos humanos ubicados en laderas, como soluciones paliativas para abordar un problema de acceso y comunicación para las familias que viven en las partes medias y altas de las pendientes (MML, 2015). En estas obras confluyen inversiones realizadas por las diferentes gestiones municipales, tanto metropolitana como distritales, así como por las comunidades locales. Sin embargo, al no ofrecer soluciones técnicas adecuadas, por un lado, configuran nuevas condiciones de riesgo y por otro lado, la aparente solución en muchos casos se convierte en un aliciente para la ocupación de nuevos terrenos ladera arriba, valorizando la parte alta de las laderas, incentivando transacciones especulativas y la configuración de nuevos riesgos y más inversiones.

Las causas de las trampas de riesgo incluyen diversos factores como bajos ingresos, planificación e infraestructura inadecuada, carencia de servicios básicos, vacíos legales, estigmas sociales y procesos inmobiliarios especulativos, entre otros. Para las mujeres y hombres que viven en condiciones de pobreza, estas circunstancias representan una mayor exposición a peligros, además de generar impactos negativos para el futuro de la ciudad. Estas trampas debilitan los esfuerzos e inversiones hechos por la gente y las agencias públicas para mitigar impactos actuales, en la misma forma en que las trampas de pobreza urbana producidas por complejas condiciones de privación urbana, debilitan los beneficios potenciales que ofrece vivir en las ciudades. Por ello la documentación y análisis de las trampas de riesgo urbano ofrece nuevas miradas al debate sobre el desarrollo, los riesgos y los desastres generando enfoques inclusivos e integrales que consideren la gestión del riesgo en forma articulada a la gestión del desarrollo.

\section{VIVIENDO EN RIESGO: URBANIZACIÓN EN RIESGO}

Lima Metropolitana, conformada por la conglomeración urbana de Lima y Callao, es una de las ciudades más dinámicas de Latinoamérica. Única ciudad costera capital en el Pacifico de América del Sur, cuenta con un legado milenario y colonial que ha influido en su diversidad cultural y ecológica. Con una dinámica industrial y económica altamente centralizada, Lima es desde la década de los 40 s un espacio que atrae procesos migratorios a nivel nacional y últimamente internacional, constituyéndose en la segunda concentración de población más alta en el mundo asentada sobre un desierto. Lima es además escenario de alta incertidumbre climática, condición que exacerba el riesgo de desastres a diferentes escalas (Bielich \& Alegre, 2015).

La población de Lima Metropolitana se ha incrementado más de diez veces desde la década de los cuarenta. En los últimos años, a pesar de haberse reducido la tasa de crecimiento, Lima aún sigue creciendo, contando en la actualidad con casi 10 millones de habitantes, de los cuales más de la mitad viven en los distritos del Este y Norte. Lima Este es el sector con mayor población, con aproximadamente 2.6 millones de residentes, siendo San Juan de Lurigancho el distrito más poblado con más de un 1 millón de habitantes (INEI, 2015). Lima Centro es el sector de distritos fundacionales de la ciudad e incluye el Distrito del Cercado de Lima que concentra barrios con significativa memoria urbana y tugurización como es el caso de Barrios Altos con su residencialidad resistente a la constante amenaza de la erradicación (de los Ríos Bernardini, 2006, 2009). En Lima y Callao se encuentra la línea de pobreza extrema urbana más alta del Perú. Según los cálculos y la metodología del INEI al 2011 casi un millón y medio de personas en estas áreas no llegaban a cubrir los costos de la canasta básica familiar. En el mismo año, el hacinamiento en Lima Metropolitana muestra el incremento porcentual más alto del país (Vásquez Huamán, 2012). 
Por otro lado, los ríos estacionales de Lima Metropolitana sufren de escasez hídrica, por ello el abastecimiento de agua en la ciudad depende de las lluvias en los Andes y grandes obras de infraestructura para transferir agua de la cuenca del Atlántico a la cuenca del Pacifico y así satisfacer la demanda de la industria, el comercio y la población urbana. A pesar de dichos esfuerzos, más de un millón de habitantes no tienen conexiones de agua potable ni saneamiento; debido en parte al proceso de expansión informal especulativa que produce una dinámica de ocupación del territorio dispersa y no planificada, lo cual dificulta la atención de los entes estatales y la expansión de servicios básicos de red. Por otro lado la provisión de servicios cuando llega a abastecer a nuevos asentamientos incrementa el valor del suelo de las áreas mejoradas pero también incrementa las expectativas de ganancias en terrenos aledaños, promoviendo la acción de especuladores urbanos y resultando en la creación de nuevos asentamientos informales que reproducen nuevas condiciones de riesgo para más familias. Además, la degradación física, social y ambiental, y las condiciones de pobreza existentes en diversas zonas aumentan la vulnerabilidad y exposición a riesgos de manera reiterada. Estas condiciones resultan en círculos viciosos de reproducción de riesgo, en tanto la gestión de la ciudad privilegia procesos especulativos y no provee alternativas reales de acceso a la tierra, vivienda y servicios para amplios sectores de la población.

La ciudad se caracteriza por su escaza preparación ante fenómenos climatológicos de cierta magnitud, tales como los pronosticados a finales del año 2015 y el primer trimestre de 2016 y 2017 debido a la presencia del Fenómeno El Niño (FEN) con impactos moderados a extremos. Esto generó la declaración de emergencia de 14 regiones del Perú, incluida Lima, debido a lloviznas constantes, alta humedad, probables desbordes de ríos, huaicos más fuertes y violentos que el verano anterior ${ }^{4}$ y deslizamientos en las jurisdicciones cercanas al mar y en los acantilados de la Costa Verde. Según un estudio del Instituto Geológico Minero y Metalúrgico (INGEMMET) en Lima Metropolitana existen 86 áreas que no resistirían un Fenómeno del Niño extraordinario, entre ellos el sector de San Juan de Lurigancho donde se ubica José Carlos Mariátegui y el Rímac, colindante y de similares características que Barrios Altos.
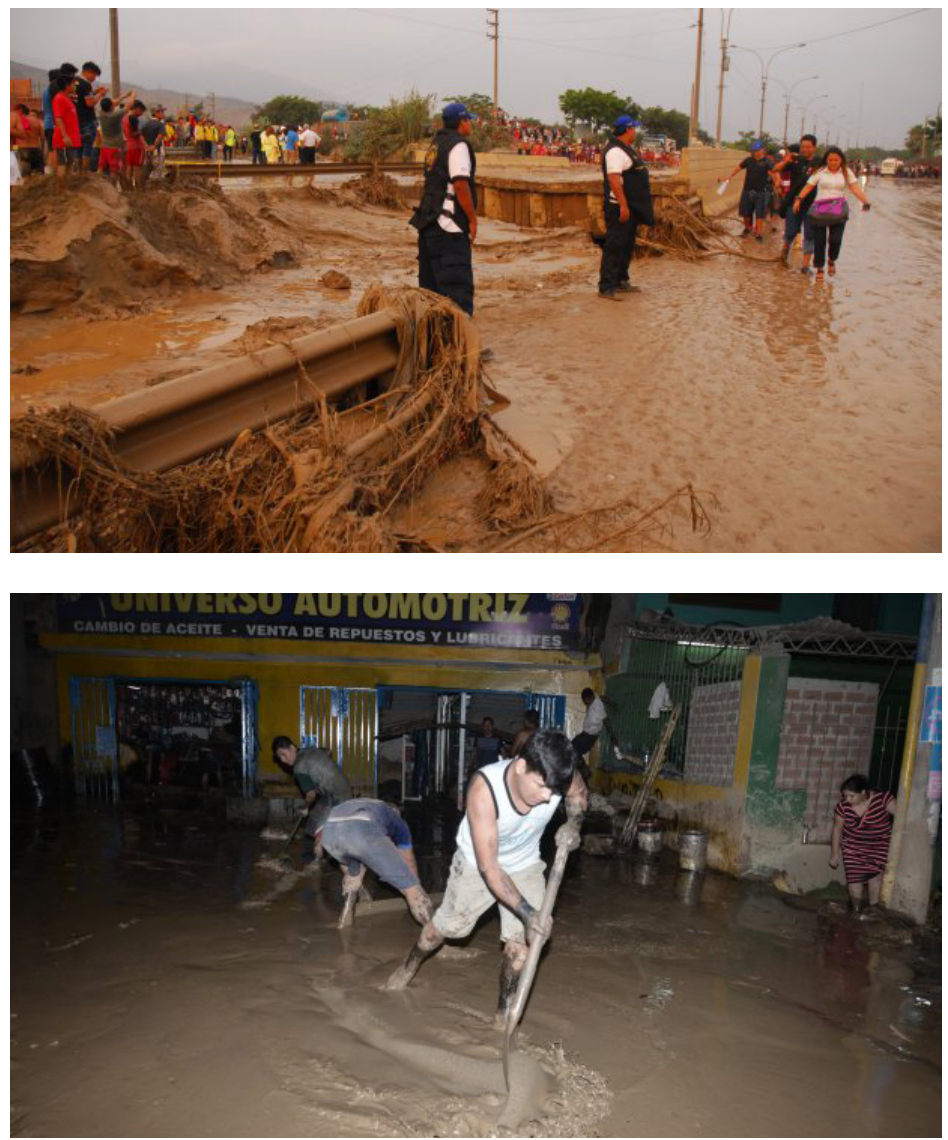

Figuras 4 y 5: Imágenes periodísticas reportando los impactos de precipitaciones repentinas que desbordaron al Río Huaycoloro inundando varias zonas de Lima, desde la periferia y hasta el centro de la ciudad.

Fuente: Diario la República (2017) en línea.
4. Declaraciones del subgerente de Defensa Civil de la Municipalidad de Lima, José Fernández. Artículo publicado en la Agencia Peruana de Noticias: ANDINA, de, 22 de julio de 2015 . 


\section{Viviendo en riesgo en el centro histórico de Lima}

Barrios Altos es parte importante de la historia e identidad de los limeños. Localizada al este del centro histórico, el área fue declarada por UNESCO como Patrimonio Mundial en 1991. Pese a su estatus histórico, el área está expuesta a una compleja red de cambios que producen y reproducen condiciones de vida inequitativas. Esta situación incide en la precariedad y la tugurización en que viven mucho de los residentes de las denominadas 'quintas' o mansiones de la etapa colonial, subdividas informalmente a través de los años y donde una familia suele habitar lo que originalmente era un cuarto (de los Ríos Bernandini, S., 2006 y 2009). Los residentes actuales enfrentan condiciones de alta vulnerabilidad en términos físicos, sociales, ambientales y económicos y están expuestos a múltiples amenazas en forma cotidiana y/o recurrente, tales como inundaciones o derrumbes por el colapso de redes de agua y desagüe en obsolescencia, incendios por cables eléctricos dañados y conexiones precarias y derrumbes de estructuras deterioradas, entre otras.
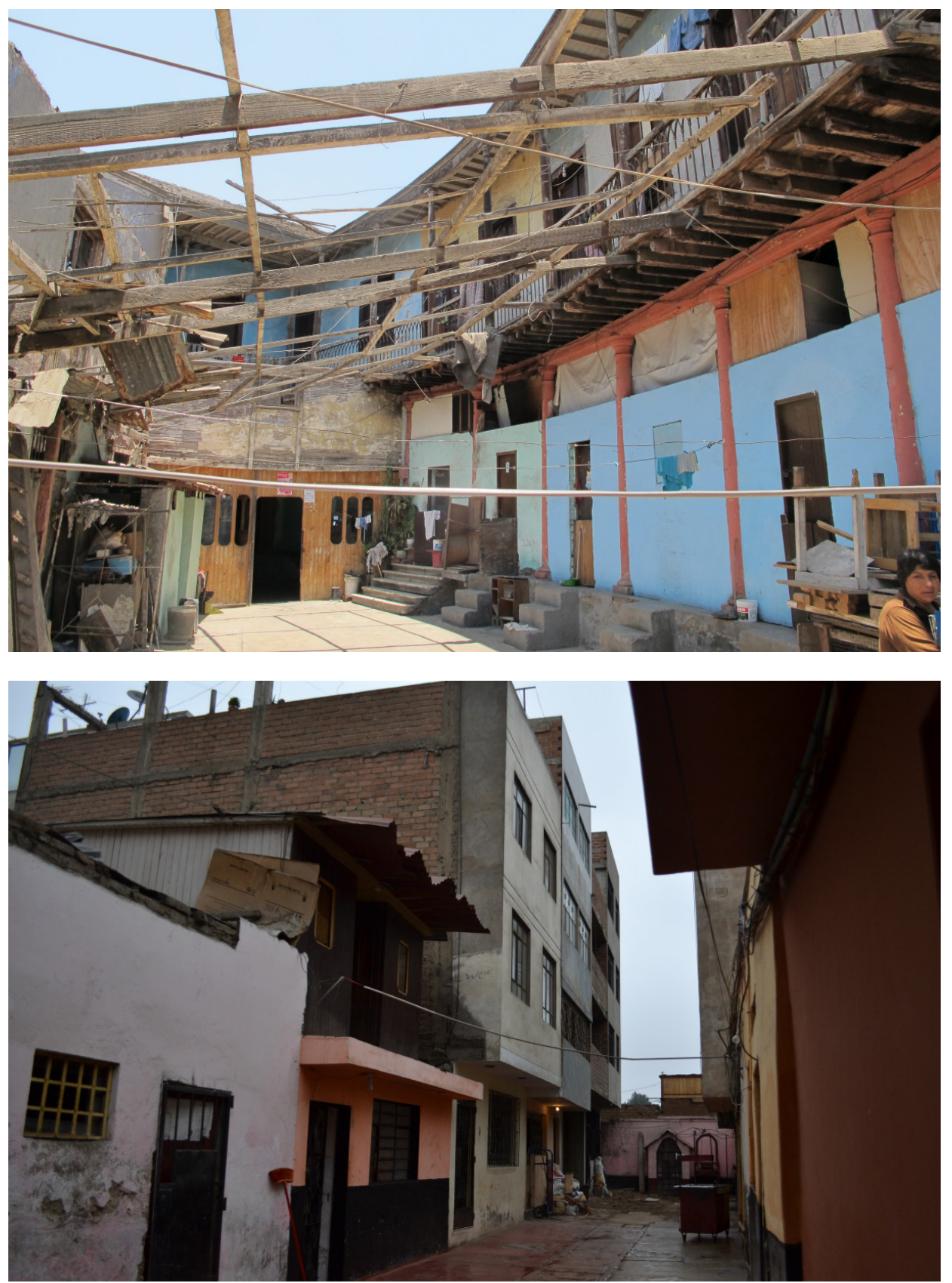

Figuras 6 y 7: Imágenes del interior de dos quintas donde las edificaciones originales se transforman a lo largo del tiempo usando materiales mixtos.

Fotos: R. Lambert 2016. 
Muchas de las edificaciones en peligro de colapso están habitadas por familias de bajos ingresos, principalmente por inquilinos y posesionarios informales ${ }^{5}$, quienes con frecuencia enfrentan desalojos forzados motivados por la especulación inmobiliaria y la valorización del área debido a su ubicación estratégica en el centro de la ciudad. Estos desalojos utilizan entre otras prácticas como la intimidación, la destrucción malintencionada de tuberías de agua, para provocar inundaciones que aceleran el debilitamiento de las estructuras y el colapso de los edificios ya frágiles, para así acelerar procesos de demolición y desarrollar negocios de rentabilidad inmediata. Asimismo, diferentes agentes privados construyen depósitos de almacenamiento en forma ilegal dentro de las quintas y detrás de las fachadas protegidas por la UNESCO, acelerando la perdida de residencialidad del área.

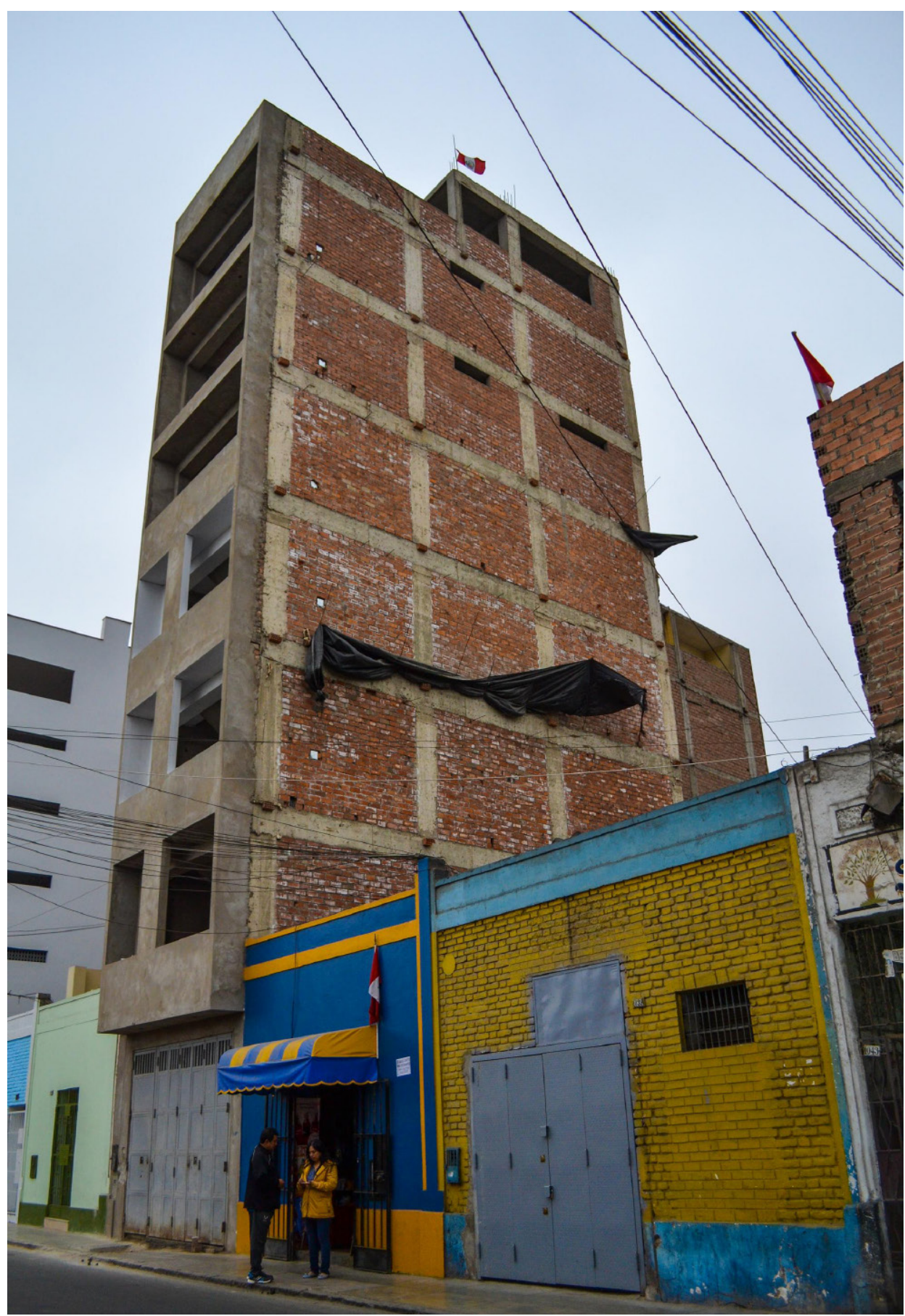

Figura 8: Reemplazo de estructuras históricas por edificaciones en altura y de mayor rentabilidad económica. Foto: T. Belkow 2016.
5. Posesionario informal o precario: Se entiende como la situación que se da cuando una persona tiene la posesión de un inmueble, sin ser su dueño. El dueño tolera dicha posesión, pero ello no significa que otorgue al poseedor ningún derecho sobre la propiedad. 
Estas actividades están rápidamente transformando el vecindario de residencial a comercial, dejando muchas calles vacías e incrementando el riesgo de incendios. Sin embargo, a pesar que las autoridades municipales están al tanto del problema, carecen de capacidad para prevenir esta situación, y por su parte las y los vecinos de Barrios Altos enfrentan grandes desafíos para responder a los riesgos cotidianos, resistir los desalojos y los cambios que están destruyendo el patrimonio cultural e histórico de su vecindario.

\section{Viviendo en riesgo en el borde de la ciudad}

José Carlos Mariátegui (JCM) incluye varios asentamientos humanos ubicados en el distrito de San Juan de Lurigancho, el más poblado y pobre de Lima y con uno de los más altos índices de inseguridad y delincuencia. Gran parte de estos asentamientos están ubicados sobre terrenos de comunidades campesinas y son frecuentemente referidos como la 'expansión de la expansión', conformando un patrón continuo y repetitivo que reconfigura el borde urbano. En ese contexto diversas oleadas de ocupación han ocurrido sobre las pronunciadas quebradas secas del distrito desde finales de 1990, inicialmente mediante ocupaciones colectivas de terrenos y más recientemente por ocupaciones individuales generadas por la demanda insatisfecha de tierra y vivienda social asequibles en otras partes de la ciudad, lo cual beneficia a los traficantes de terrenos y promueve la especulación del suelo. Esta compleja red de adquisición de tierras hace que gran parte de los residentes - en gran parte familias jóvenes, con jefas de hogar solas y una alta proporción de niños y niñas - viva sin acceso a servicios básicos y sin seguridad de tenencia, dependiendo de la asistencia esporádica de organizaciones externas y del Estado, esta última caracterizada en oportunidades por prácticas de clientelismo político (Ahmed et al., 2015; Allen et al., 2015).

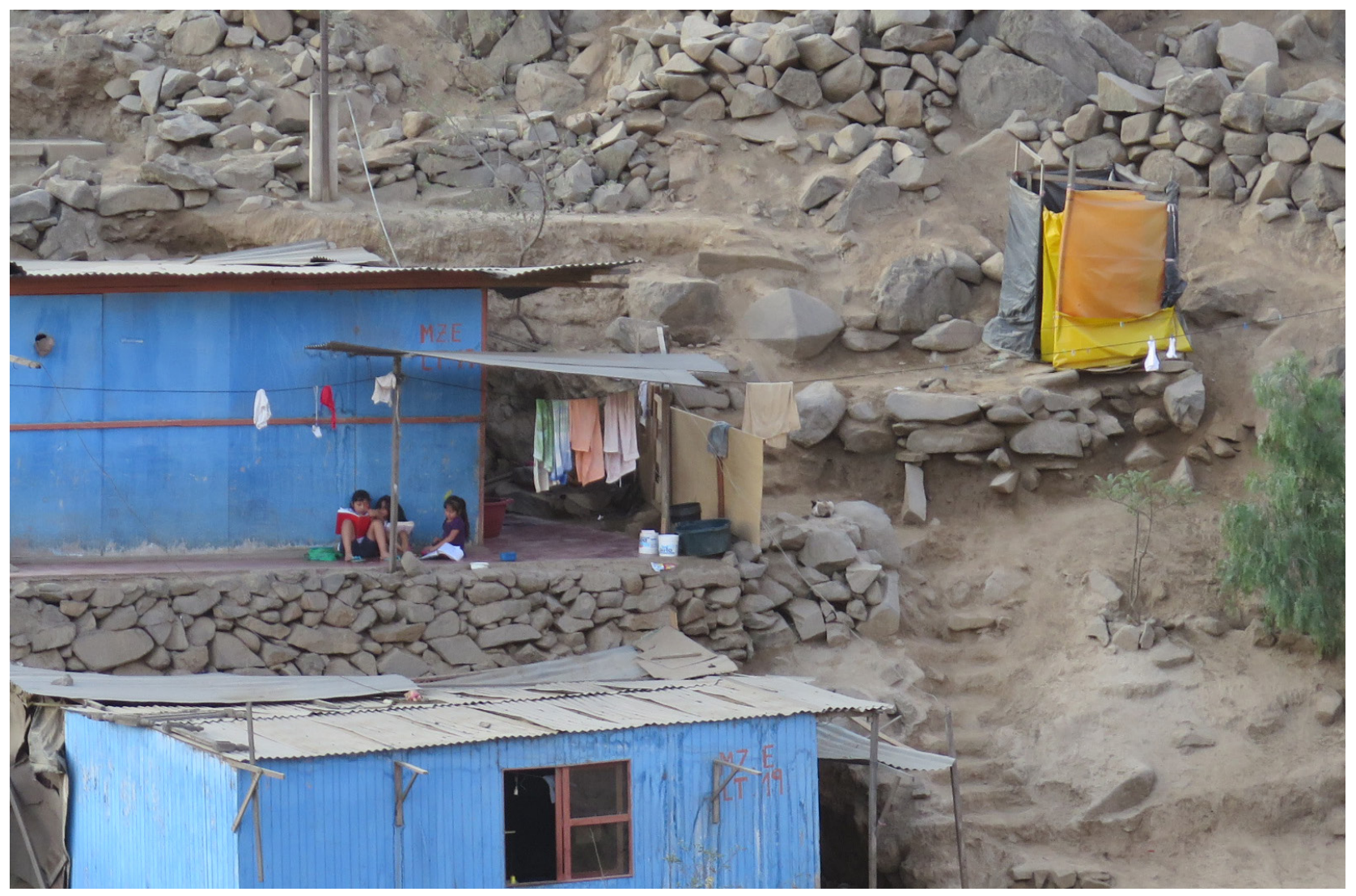

Figura 9: Condiciones de asentamiento en las partes altas de JCM. Foto: A. Allen 2016. 


\section{MAPEANDO RIESGOS COTIDIANOS Y EPISÓDICOS}

Con el objetivo de capturar espacialmente las condiciones naturales y antrópicas, así como los diversos grados de vulnerabilidad que afectan a los pobladores y pobladoras en el centro y la periferia de la ciudad, el proyecto adoptó procesos de mapeo participativo del riesgo, que produjeron información cuantitativa y cualitativa. Este proceso incluyó el mapeo conjunto por parte de miembros de ambas comunidades y representantes de instituciones públicas que trabajan el tema de riesgo, para promover el diseño de intervenciones que facilitan el desarrollo compatible con el clima, la infraestructura, la prevención y reducción de riesgos. Para una mejor comprensión de los riesgos cotidianos en cada una de estas áreas, se georreferenció en forma sistemática la información recabada, lo que permitió entender los patrones de acumulación de riesgos y dónde y cómo interrumpir las trampas de riesgo.

En BA, 187 hogares residentes en 25 quintas participaron en la encuesta, así como 158 quintas en un área de aproximadamente 40 manzanas, mientras que en JCM, 322 hogares y 13 Agrupaciones Familiares fueron encuestados entre Julio y Noviembre del 2015 (Lambert et al., 2016a, 2016b).

En JCM, $60 \%$ de los residentes encuestados dependen de soluciones colectivas para acceder al agua, lo cual implica el uso de pilones públicos, compra de agua de los vecinos y de proveedores privados que traen al agua en camiones cisterna. Aquellos hogares con conexiones a las redes de agua y desagüe dentro de sus viviendas son una minoría que vive en las partes bajas y consolidadas de la quebrada, mientras que las zonas altas habitadas más recientemente dependen de pozos ciegos y silos - pozos superficiales cercados por plásticos para dar privacidad al defecar - ubicados en las zonas aún no habitadas. La mayoría de los hogares encuestados tienen instalaciones eléctricas dentro de la vivienda, pero estas conexiones crean riesgos debido a la precariedad de cajas eléctricas y cables expuestos. Afuera de las viviendas predomina la falta de iluminación pública en combinación con malos accesos, lo cual incrementa el riesgo de accidentes. La Figura 10 muestra que una gran parte de hogares están afectados por múltiples riesgos simultáneos y en forma frecuente.
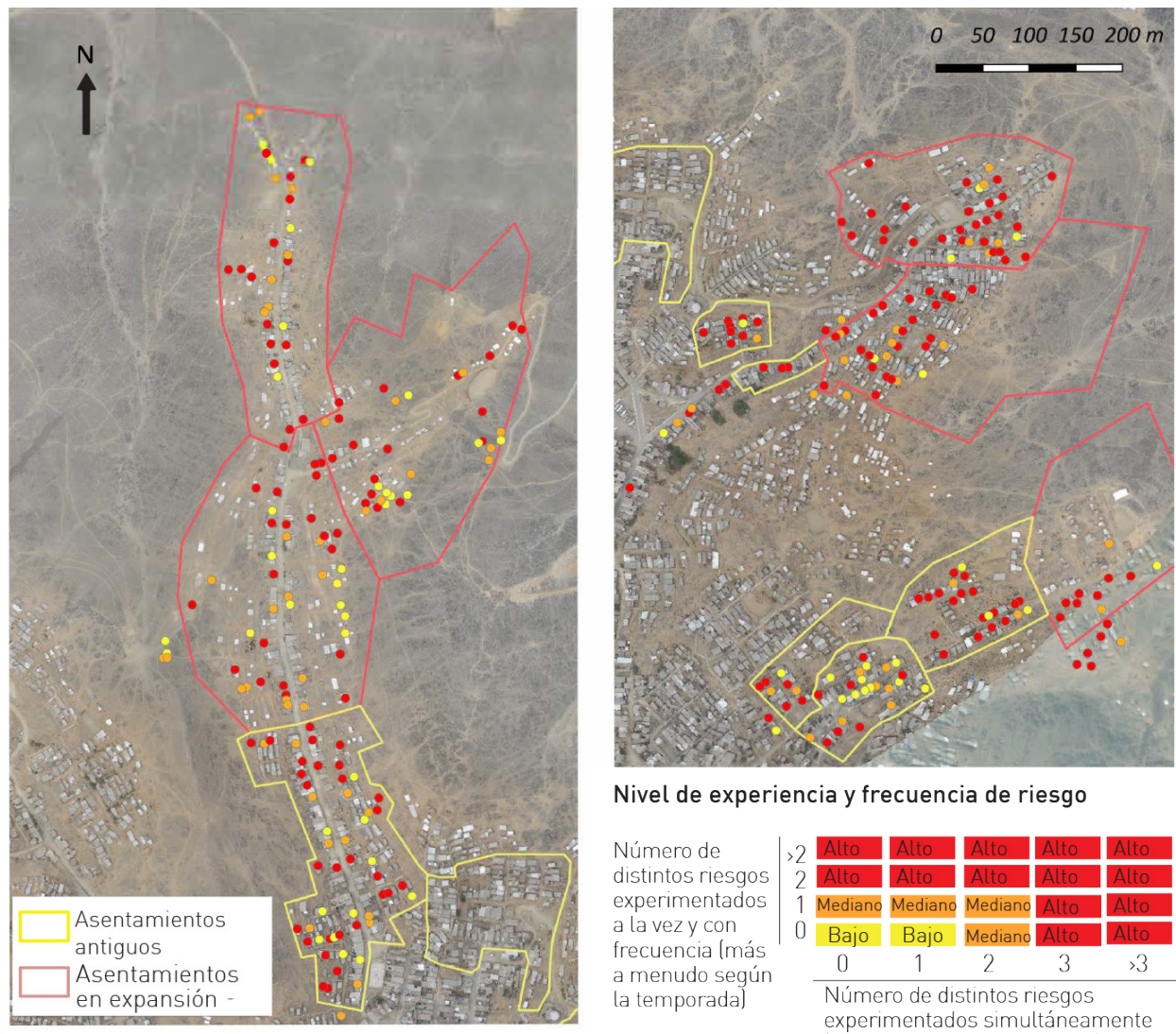

Nivel de experiencia y frecuencia de riesgo

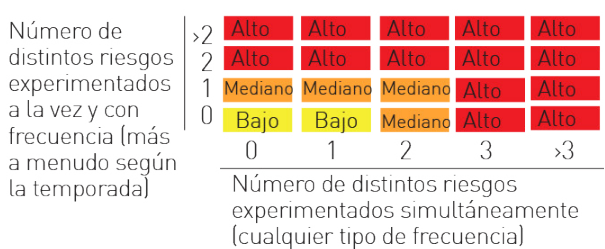

Figura 10: Nivel de experiencia y frecuencia de riesgo en los asentamientos encuestados en JCM. Fuente: cLIMA sin Riesgo (2016). 
En Barrios Altos (BA), casi dos tercios de los jefes de hogar encuestados nacieron en la zona y viven en condiciones de tugurio, sin seguridad de tenencia y con infraestructura deteriorada). La proximidad entre quintas residenciales y otros usos de suelo tales como almacenes o plantas de carga de combustibles, explica la alta exposición de los hogares a riesgos de incendios, colapso estructural e inseguridad en BA. De las 158 quintas encuestadas, el $25 \%$ registra uso mixto de suelo dentro del lote (Figura 11).
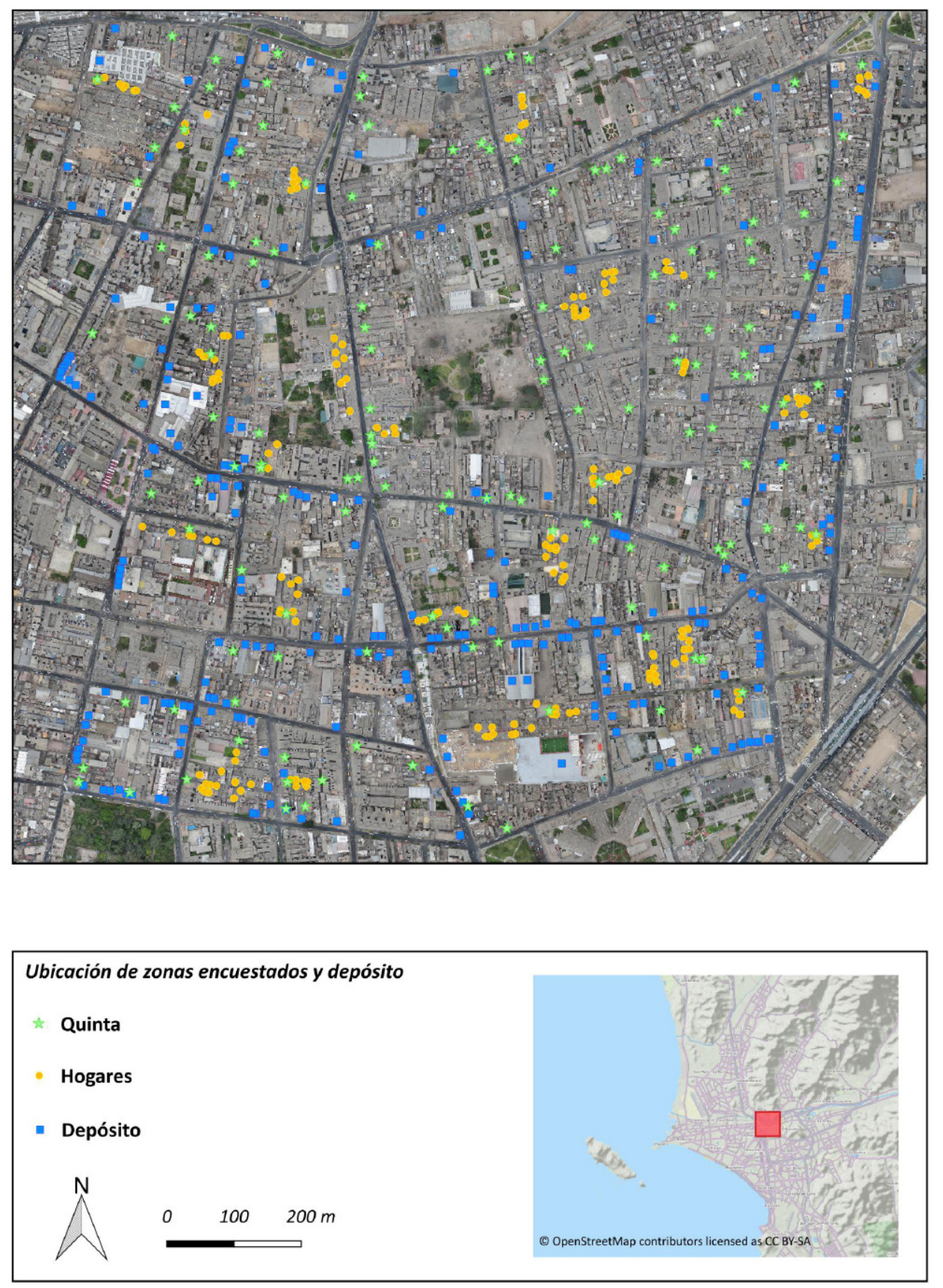

Figura 11: Ubicación de depósitos y almacenes en proximidad de las quintas y viviendas encuestadas. Elaboración: cLIMA sin Riesgo (2016). 
Los resultados de las encuestas se visualizaron en una plataforma digital en línea llamada Mapas Parlantes 6 . Esta plataforma está basada en el Sistema de Información Geográfica (GIS) de ESRI, el que permite visualizar fácilmente información cualitativa y cuantitativa y acceder a narrativas, fotografías y testimonios de los pobladores sobre lo que significa la experiencia de vivir en riesgo (Lambert et al., 2016a, 2016b). La base de los mapas parlante son imágenes de drones de alta resolución de ambas zonas y la información almacenada está organizada a través de diferentes temas claves en cada área de estudio.

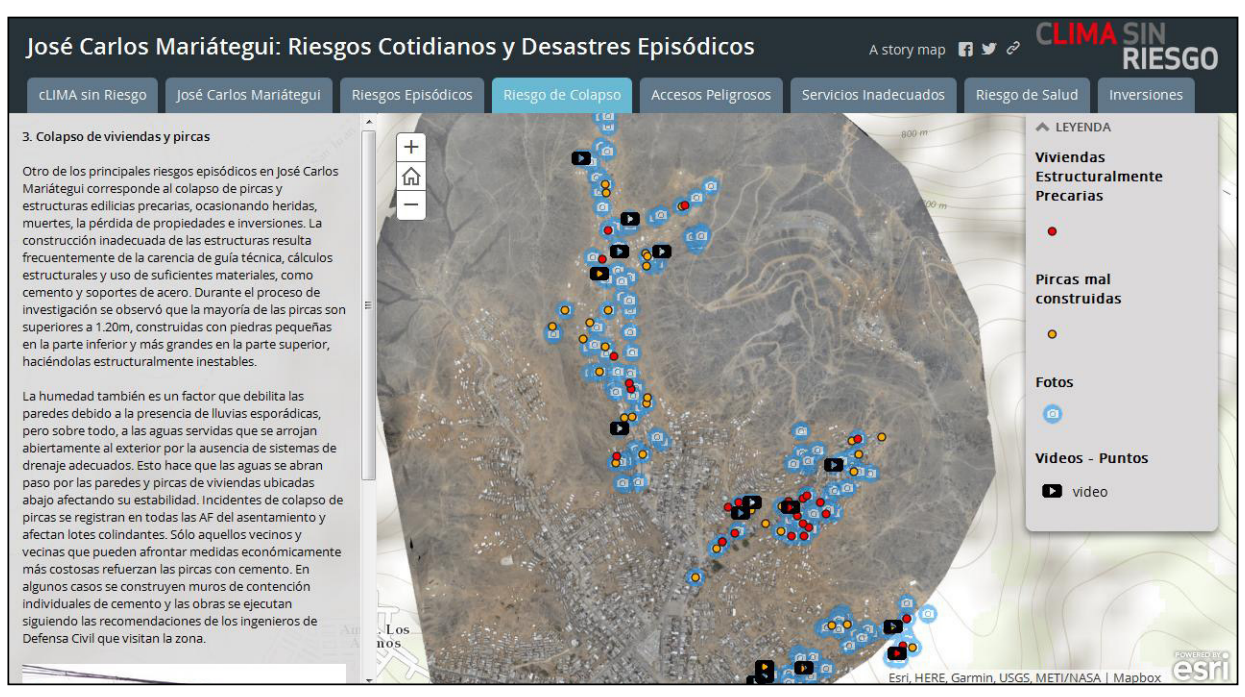

Figura 12: El Mapa Parlante de JCM visualiza los diferentes tipos de riesgos cotidianos en la zona. Fuente: Lambert et al., (2016a).

Foto: cLIMA sin Riesgo 2016.

En forma adicional, para sistematizar la documentación de riesgos, cLIMA sin Riesgo desarrolló una plataforma en línea llamada ReMapRisk que puede accederse públicamente. La herramienta permite a los residentes locales registrar y monitorear cómo y dónde se materializan los ciclos de acumulación de riesgo a lo largo del tiempo; además se pueden producir mapas a diferentes escalas en respuesta a consultas que combinan múltiples variables.

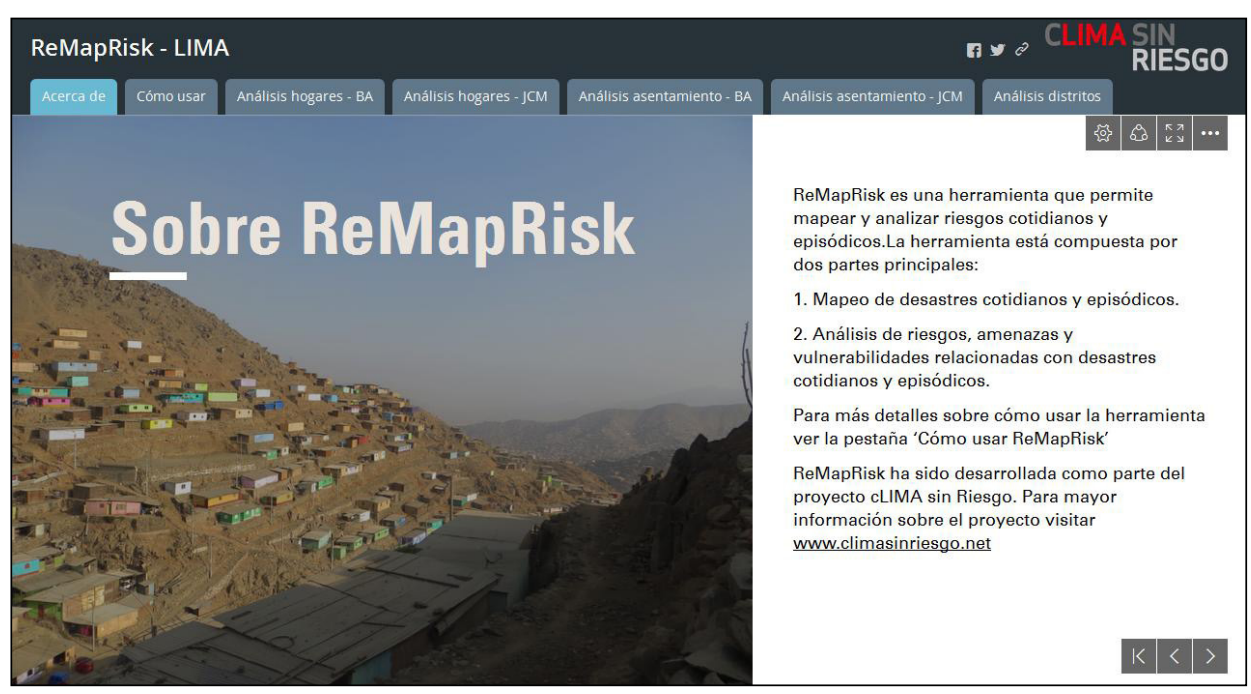

Figura 13: ReMapRisk Lima, plataforma virtual interactiva accesible desde http://www.climasinriesgo.net. Foto: cLIMA sin Riesgo 2016.
6. Los enlaces a los mapas parlantes son los siguientes: Barrios Altos http://arcg.is/1FkV5MD; José Carlos Mariátegui - http://arcg.is/1hCMRcV. 
La base cartográfica utilizada son también imágenes de alta resolución tomadas por drones en cada una de las áreas de estudio. Estas imágenes facilitaron el mapeo simultáneo en forma manual y digital, este último auxiliado con el uso de teléfonos inteligentes o Smartphones y de la aplicación Survey 123, que permite la digitalización casi inmediata de la información relevada y su visualización en ReMapRisk (Lambert \& Allen, 2016). Con el apoyo de tres observatorios establecidos por el proyecto, los habitantes locales podrán informar sobre los eventos de riesgo y desastres a pequeña escala a medida que ocurren (Allen et al., 2017).

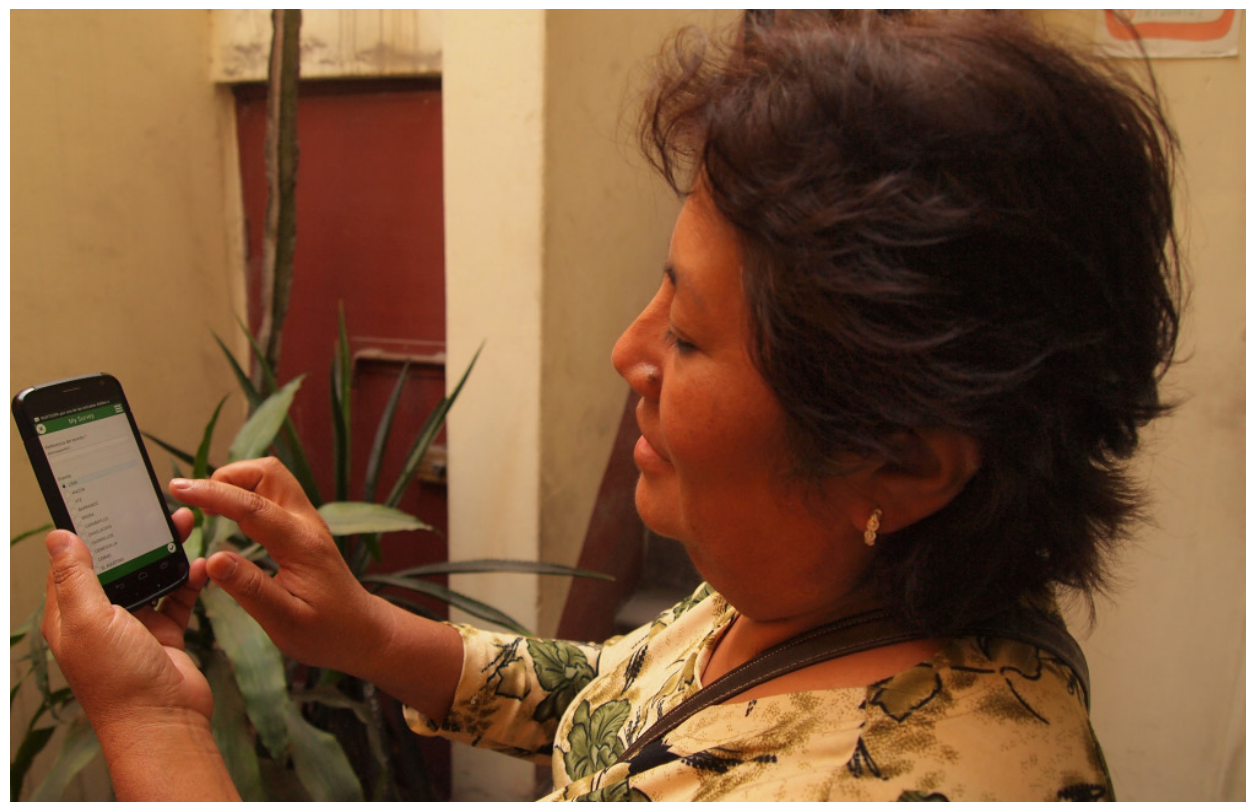

Figura 14: Vecina en Barrios Altos participando del mapeo comunitario de su barrio. Foto: F. Benítez 2016.

La recogida de datos abarcó una muestra representativa en ambas localidades. En Barrios Altos se cubrieron 40 manzanas (lo cual representa la mitad del área), donde el 30\% de los hogares en quintas en cada manzana fueron encuestados. En José Carlos Mariátegui se encuestó el $30 \%$ de las parcelas ocupadas dentro de los 12 asentamientos incluidos en el estudio. El carácter participativo del proceso implicó la integración de los residentes en el diseño de la encuesta y la compilación de datos, creando oportunidades para construir nuevas capacidades y fortalecer los procesos existentes de formación de redes y movilización social, facilitando la acción colectiva y la resistencia a cambios no deseados.

En las agrupaciones de José Carlos Mariátegui, la identificación de las diferentes inversiones realizadas a lo largo del tiempo, permitió visualizar tanto los impactos deseados como no deseados generados por dichas inversiones, elevando la concientización sobre el efecto dominó que se genera por acciones atomizadas sobre el territorio y abriendo nuevos caminos hacia una planificación integrada entre los asentamientos y en colaboración con agencias estatales.

Los resultados sugieren que las medidas adoptadas para mitigar riesgos en un sitio, frecuentemente externalizan el riesgo a otros lugares. Mapear y visibilizar las interdependencias constitutivas que dan forma a un determinado territorio, es vital para encontrar soluciones de forma integrada y producida en conjunto con todos los actores claves.

La noción de interdependencias se materializa a diferentes escalas, tanto en Barrios Altos como en José Carlos Mariátegui, por lo cual el análisis abordó varias escalas y etapas. En Barrios Altos, en algunas de las quintas donde la mayoría de los vecinos son propietarios, se verifica una organización social debilitada. En estos casos, las quintas que anteriormente funcionaban con objetivos colectivos para la mejora y mantenimiento de áreas y servicios comunes, ahora actúan desde prácticas individuales. Esto significa que algunos hogares realizan obras de mejora fragmentadas y con frecuencia reemplazan la estructura tradicional de materiales de quincha $y / 0$ adobe por estructuras de múltiples pisos de ladrillo y cemento. A medida que la integridad estructural de las edificaciones se debilita, debido al uso de materiales mixtos, los residentes se encuentran 
diferencialmente expuestos a mayores riesgos. Esto, más la debilitación de la organización y acción colectiva, aumenta la vulnerabilidad frente las actividades especulativas de terrenos. A escala de manzana, es posible captar otros riesgos que abundan en el centro histórico. La especulación del suelo está dando lugar a desalojos que perjudican a los inquilinos más vulnerables. Asimismo, el crecimiento de instalaciones usadas como almacenamiento, aumenta la probabilidad de incendios debido al depósito de materiales altamente inflamables, aumentando los riesgos a que están sujetos las quintas colindantes y sus habitantes.

En José Carlos Mariátegui las interdependencias se materializan en la ladera. El riesgo se distribuye de forma desigual, siendo que los que viven más arriba en la pendiente, son los que tienen que pagar más para mitigar riesgos y mejorar las condiciones de habitabilidad del área. La ocupación de las partes altas, tanto desde las prácticas adoptadas por los traficantes de terrenos a gran escala, como desde la apertura de caminos para aprovechar las ganancias de terrenos ubicados en sitios altos, aumenta el riesgo de caída de rocas sobre las áreas más bajas. La cartografía y líneas de tiempo a escala de asentamiento, permite visibilizar las inversiones realizadas a lo largo del tiempo y donde y como estas mejoran las condiciones de habitabilidad en forma altamente localizada y, a menudo, externalizando nuevos riesgos a otros asentamientos (Figura 15). Estos procesos sólo pueden captarse a una escala más micro y específica de la adoptada en la producción de mapas oficiales, los cuales tienden a homogenizar las condiciones de riesgo.

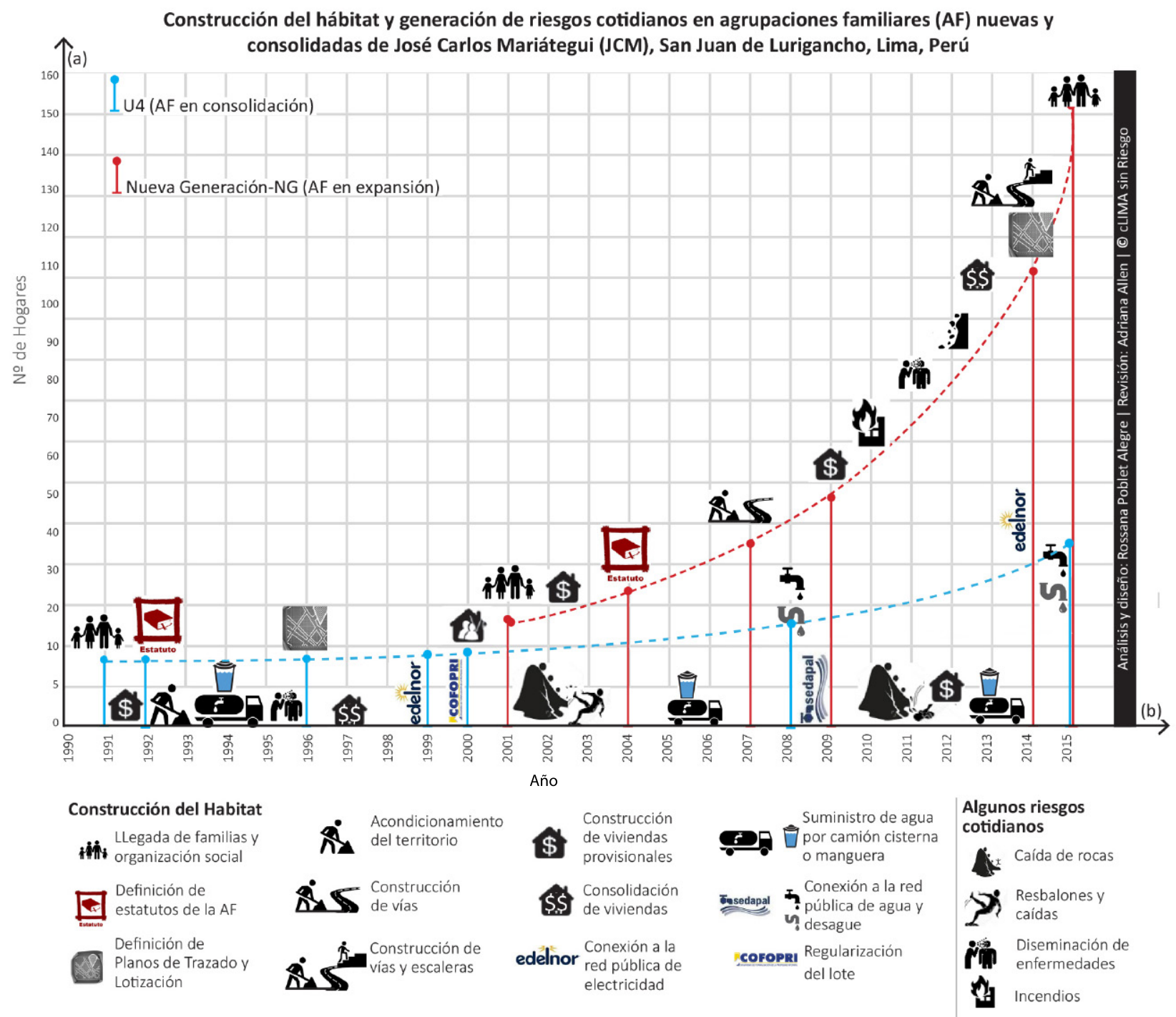

Figura 15: Línea de tiempo de dos asentamientos en JCM.

Elaboración: R. Poblet 2016

Fuente: Allen et al. (2016). 


\section{EVALUANDO FLUJOS DE INVERSIÓN EN MITIGACIÓN DE RIESGOS}

El análisis de los flujos de inversión en mitigación de riesgos está vinculado a la valorización real del riesgo, e involucra el examen de los programas y mecanismos de financiamiento público, las acciones y medidas desarrolladas e intervenciones recientes, así como una estimación de las inversiones realizadas por los mismos pobladores y pobladoras para mejorar sus viviendas y vecindarios y mitigar riesgos en forma cotidiana. Este proceso permitió comprender tanto el peso relativo de diferentes grados de vulnerabilidad al riesgo, como la capacidad de respuesta y recuperación de los habitantes más desfavorecidos en el centro y la periferia de la ciudad.

A nivel de Lima Metropolitana, los actores que en la práctica están relacionados a la gestión del riesgo incluyen al gobierno central, gobiernos regionales y locales, organismos internacionales y de cooperación, organizaciones no-gubernamentales y redes de cooperación nacionales e internacionales, colegios profesionales y la comunidad científica, así como los hombres y mujeres que configuran las condiciones de habitabilidad del territorio y son actores principales de su gestión.

En la última década se registra en Perú un cambio significativo en la conceptualización e instrumentación del sistema público de Gestión de Riesgo de Desastres (GRD), que se inicia en enero del 2011 con la adopción de la Ley N² 29664 y la creación del Sistema Nacional de Gestión de Riesgos de Desastre (SINAGERD) (SGRD 2015). Este marco de gestión pública fue acompañado por el incremento de los recursos financieros y el uso de mecanismos de financiamiento público orientados a la gestión del riesgo de desastres, principalmente en los niveles central y regional. Actualmente se cuenta con el Programa Presupuestal 0068 (PP 0068) "Reducción de la Vulnerabilidad y Atención de Emergencias por Desastres" (PREVAED); programas de transferencias condicionadas e incentivos y fondos concursables, dentro de los que se encuentra el Plan de Incentivos a la Mejora de Gestión y Modernización Municipal (PIM) y el Fondo de Promoción para la Inversión Pública Regional y Local (FONIPREL); recursos presupuestales de las entidades públicas identificadas en otras categorías presupuestales (por ejemplo: obras por impuestos, recursos del Canon, etc.); Reserva de Contingencia y Líneas de Crédito Contingentes; Fondo de Estabilización Fiscal; y Presupuestos Participativos; entre otros.

Estos recursos han promovido el desarrollo de sistemas de información apoyar la GRD a nivel nacional, la disposición de recursos de ayuda humanitaria para atender emergencias mayores, el monitoreo y mapeo de peligros naturales, obras de protección y mejoras en la seguridad de edificaciones y servicios esenciales tales como hospitales y escuelas seguras. Sin embargo, pese a que la incidencia del PREVAED en el presupuesto total del Sector Público se incrementó de $0.07 \%$ en 2011 a $0.7 \%$ en 2014 y el nivel de ejecución también registró una mejoría (de 56\% en 2011 a 77\% en 2014), estas inversiones solo representaron poco más del 1\% del presupuesto del Sector Público en el 2014, fondo que con frecuencia no es ejecutado por los gobiernos sub-nacionales (Allen et al., 2016).

La actual administración de la Municipalidad Metropolitana de Lima (MML) ha anunciado dos programas para el centro y la periferia que comprenden la inversión de más de 60 millones de soles para la construcción de escaleras y losas deportivas en los distritos de Independencia y Villa María del Triunfo en su primera fase (MML, 2015) y un convenio de cooperación interinstitucional con el Ministerio de Vivienda, Construcción y Saneamiento (MVCS) que permitirá acceder a la maquinaria y vehículos para tomar acciones en caso de emergencia y desastres y la realización de actividades conjuntas en prevención y mitigación de riesgos, a través del Programa Nuestras Ciudades. La anterior gestión de la MML (2011-2014) abordó el tema de mitigación de riesgos mediante el Programa Barrio Mío (PBM) y el Plan de Mitigación de Riesgos en Laderas (PMRL). Ambos tenían por objetivo mejorar barrios, mitigar riesgos y por ende mejorar la calidad de vida de aquellos en condiciones de pobreza. Según fuentes de la MML, hasta el 2014, estos programas canalizaron recursos para la construcción de 1200 escaleras y 800 muros de contención integrados en sistemas urbanos de emergencia en 20 distritos. Por su parte Barrio Mío a través de los Planes Urbanos Integrales identificó proyectos para mejorar barrios (construcción de equipamiento social), reducir riesgos (construcción de muros de contención, escaleras, y reubicación de viviendas), y definir planes y proyectos a través del Plan Metropolitano de Desarrollo Urbano de Lima y Callao (PLAM 2035) (MML 2014). Estos programas fueron abandonados con el cambio de la administración municipal, lo cual dificulta la evaluación de los impactos alcanzados en la mitigación de riesgos. Recientemente el Ministerio de Vivienda ha lanzado un programa para otorgar un bono de protección a viviendas vulnerables ante riesgos sísmicos que permitiría a las familias reforzar sus viviendas pero que sólo abarca a las familias con título de propiedad, excluyendo a las familias que no cuentan con título de sus terrenos y que frecuentemente son las más vulnerables (Allen et al., 2016). 
La Rueda de Gestión del Riesgo describe las acciones propuestas y/o implementadas por instituciones públicas a través de diferentes programas y proyectos, así como las prácticas colectivas e individuales adoptadas por vecinos y vecinas en condiciones de vulnerabilidad para mitigar diversos riesgos en la periferia de la ciudad. La Figura 16 ejemplifica la situación existente en José Carlos Mariátegui y ayuda a entender cuáles son los esfuerzos desplegados por diferentes actores en forma simultánea sobre un territorio especifico. Sin embargo, frecuentemente, estos esfuerzos e inversiones son desarticulados y sin planificación a futuro y por lo tanto insuficientes para interrumpir las trampas de riesgo.

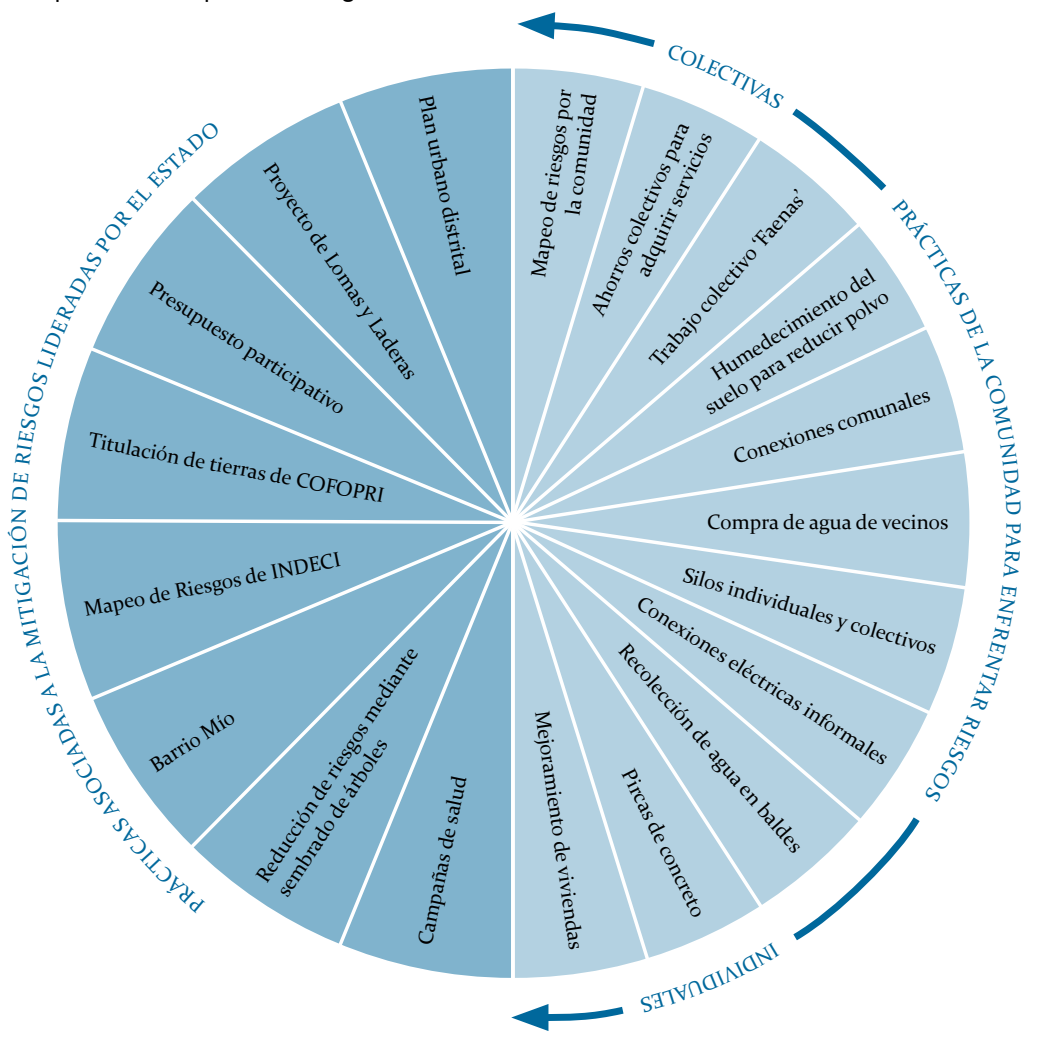

Figura 16: La Rueda de Gestión del Riesgo muestra prácticas comunitarias, colectivas y estatales para enfrentar riesgos. Fuente: Allen (2015)

La paradoja de la periferia de la ciudad es que la poca inversión inicial requerida para ocupar un terreno en estas áreas se multiplica en el tiempo ya que las familias deben invertir costos elevados para crear condiciones de habitabilidad sobre las fuertes pendientes carentes de servicios básicos. Las inversiones realizadas para mejorar la habitabilidad progresivamente resulta en la construcción de los propios riesgos. Por ejemplo, al aplanar terrenos en las partes altas de las laderas se construyen muretes de piedras llamados pircas, práctica que incrementa el riesgo de deslizamiento de piedras; asimismo los vecinos construyen empinadas escaleras para acceder a las partes más altas, con pasos irregulares y sin barandas, lo cual provoca frecuentes resbalones y accidentes. Como resultado, tanto los riesgos cotidianos como los desastres de menor escala tienden a acumularse e intensificarse a lo largo del tiempo, exacerbando los retos experimentados por la población marginal en situación de pobreza y empujándolos más profundamente en trampas de riesgo que no pueden ser revertidas por respuestas individuales (Allen et al., 2015).

\section{ACCIÓN ESTRATÉGICA Y PLANIFICACIÓN DE ESCENARIOS}

Como fue señalado en la introducción, el desarrollo futuro de Lima Metropolitano está afectado por altas condiciones de incertidumbre climática, condiciones que exacerban la ocurrencia de fenómenos de desastres a escala menor y mayor. En el estudio Lima, Vulnerabilidad Climática al 2040 (Miranda, Torres \& Arana, 2015), y en la Estrategia de Adaptación y Mitigación al Cambio Climático de Lima aprobada por Ordenanza Municipal en Diciembre del 2014, se identificaron los siguientes escenarios climáticos plausibles presentados y validados por expertos locales: ${ }^{7}$ 
- Escenario 1: Condiciones de tropicalización con lluvias intensas, aumento de temperatura de al menos $2^{\circ} \mathrm{C}$ y aumento de caudal de al menos $13 \%$;

- Escenario 2: Condiciones de temperización, con reducción de precipitación y caudal, sequías y baja de temperatura, parecido a situaciones como La Niña; y,

- Escenario 3: Mayor frecuencia de El Niño, con condiciones alternadas de los escenarios 1 y 3; en base a los cuales se exploran las relaciones espaciales entre la exposición al riesgo y su conexión con la situación de desigualdad en la ciudad. Las amenazas asociadas al escenario 1 están relacionadas a la probabilidad de ocurrencia de tres tipos de eventos, lluvias intensas, huaycos e inundaciones y olas de calor, fenómenos con alta probabilidad de ocurrencia en Lima ante el FEN 2015-2016

Considerando estos escenarios climáticos, como parte del proyecto se desarrollaron talleres multi-actorales para la construcción y análisis de tendencias y proyecciones multivariables, a escala local, lo cual permitió desarrollar procesos de construcción social del conocimiento territorial y evaluar las capacidades necesarias para generar cambios que dependen de cómo y cuán rápido las poblaciones, autoridades, sector privado y sociedad civil se organicen y adapten para manejar los impactos esperados. Los talleres permitieron construir mutuos entendimientos, combinando una variedad de conocimientos (tácito/basado en la experiencia y experto/codificado) en cada área de estudio; así como avanzar en la identificación de acciones estratégicas en el corto, mediano y largo plazo.

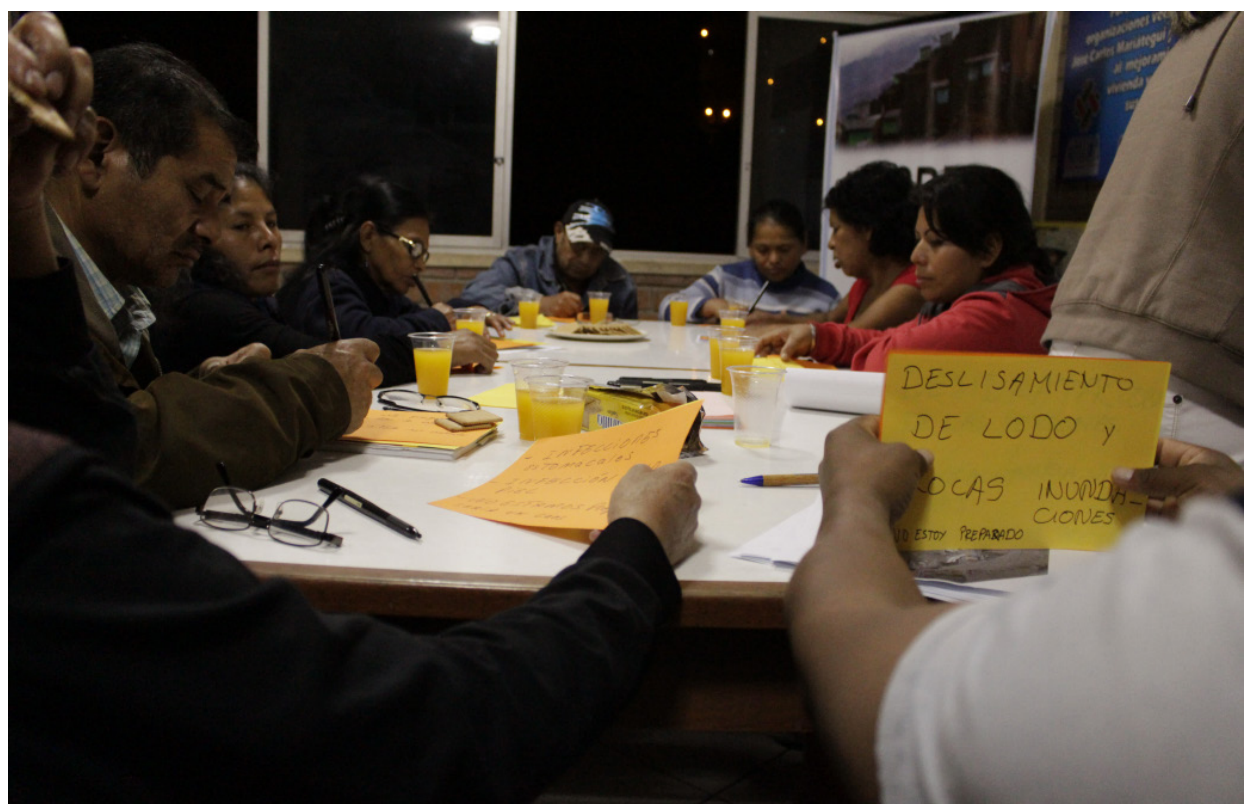

Figura 17: Taller de escenarios climáticos con residentes de JCM. Foto: F. Espinoza 2016 .

Esta metodología ofrece la oportunidad de evaluar diferentes cursos de acción en la lógica de "¿qué pasaría si?", y así capturar la diferencia entre un futuro 'con o sin riesgos.' Este proceso también permitió contribuir en la elaboración participativa de planes de desarrollo que incorporen iniciativas en curso en la gestión del riesgo y planes de prevención y reducción de riesgos, a través del diálogo.

Para apoyar la participación gradual de más actores y asegurar la implementación de acciones concertadas entre diferentes sectores, cLIMA sin Riesgo creó tres plataformas de aprendizaje-acción u observatorios con los socios locales: uno centrado en la periferia de la ciudad, alojado por el Instituto de Desarrollo Urbano (CENCA); el segundo en el centro histórico, coordinado por el Centro de Investigación, Documentación y Asesoría Poblacional (CIDAP); y el tercero, vinculado a las intervenciones en la zona Metropolitana de Lima, coordinado por Foro Ciudades para la Vida (FCPV). Los observatorios forman parte del legado del proyecto y tienen como objetivo divulgar y consolidar los resultados de la investigación, ampliar el debate y la formación de redes para la acción para combatir los procesos actuales de desarrollo urbano en riesgo (Allen et al., 2017a). 
En agosto de 2016, el proyecto lanzó una convocatoria pública de proyectos innovadores, donde las comunidades locales de Barrios Altos y José Carlos Mariátegui co-diseñaron con organizaciones externas proyectos de reducción de riesgos cotidianos en su entorno construido. Doce propuestas fueron presentadas y seis implementadas, entre ellas, un proyecto de reducción de vulnerabilidad entre adultos jóvenes mediante el desarrollo de áreas recreativas en Barrios Altos; experimentos con cosecha de agua y el uso de aguas residuales para la producción de alimentos impulsado por un colegio local; y el diseño de un programa de vivienda social multifamiliar que aprovecha el uso de los aires en áreas consolidadas para reducir la ocupación de laderas en José Carlos Mariátegui (Allen et al., 2017b). Los proyectos ofrecen un terreno fértil para considerar cómo intervenciones concretas pueden abordar las trampas de riesgo y crear sinergia entre las capacidades de acción de distintos actores.

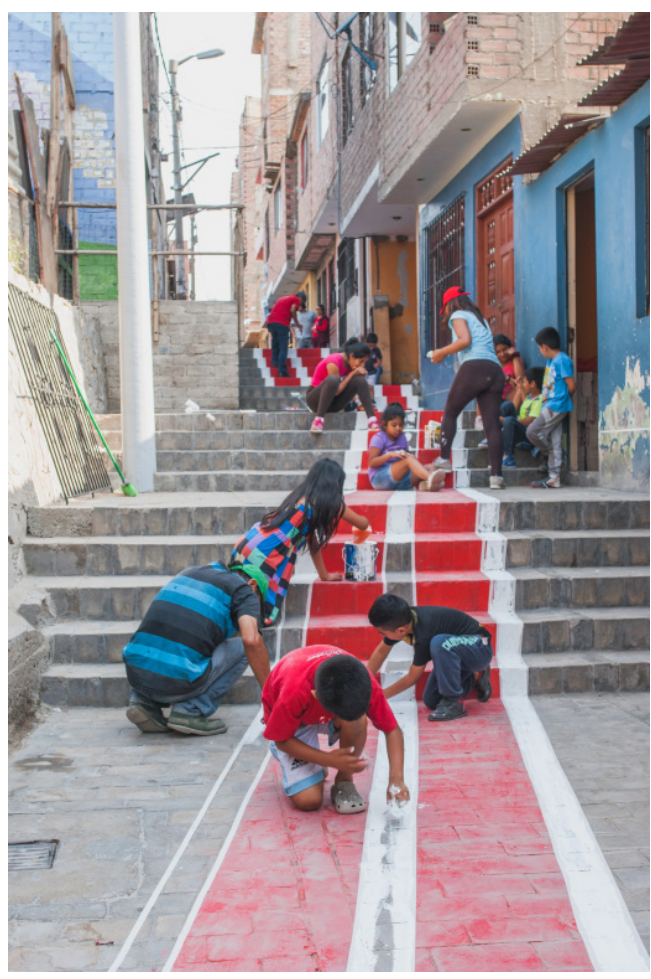

Figura 18: Trabajo participativo en uno de los proyectos ganadores para la reducción de riesgos en Barrios Altos, Jardín Primavera - Barrio de los Niños Foto: E. Cuadros 2016.
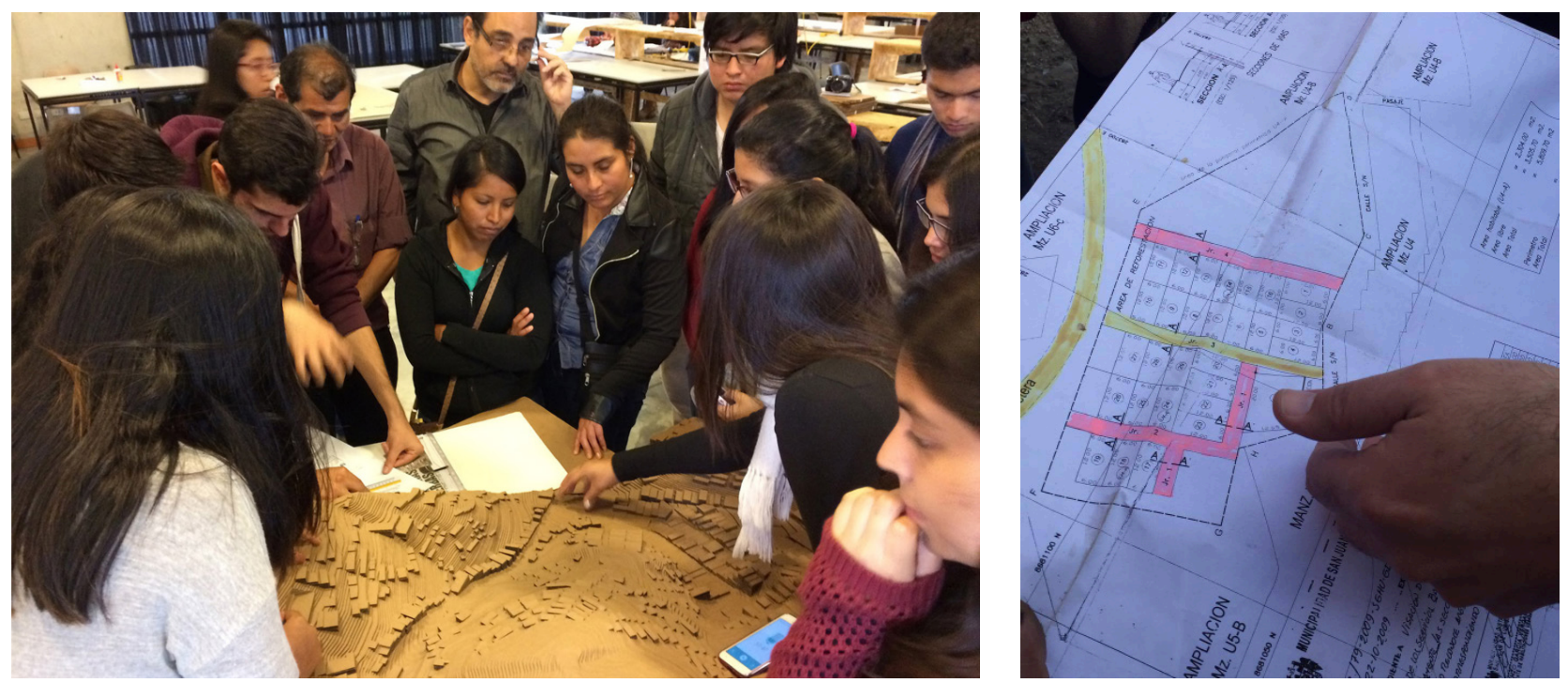

Figuras 19 y 20: Miembros del equipo ganador presentan un modelo de intervención que fue propuesto a los residentes de la zona (izquierda); mapa de asentamiento (derecha). Foto: Taller 4, FAU-PUCP, S. Lasso 2016. 
La estrategia de comunicación de resultados del proyecto y la diseminación de rutas estratégicas para la acción fue apoyada por varios medios, incluyendo la publicación de boletines comunitarios, documentos de perspectivas para la acción y videos que resumen los hallazgos; materiales accesibles en línea de la página web. En Lima se desarrolló también una exhibición viajante que comparte la metodología y resultados del proceso de mapeo participativo, la cual fue visitada por más de 6000 personas en cuatro puntos estratégicos de la ciudad durante 2015 y 2016. Una exhibición pública bilingüe con los resultados de todo el proceso se presentó en la cumbre de Hábitat III en Quito, así como en Londres y en forma virtual, ofreciendo una actualización de contenido que paneles, mapas y modelos, videos, Mapas Parlantes y otros materiales.

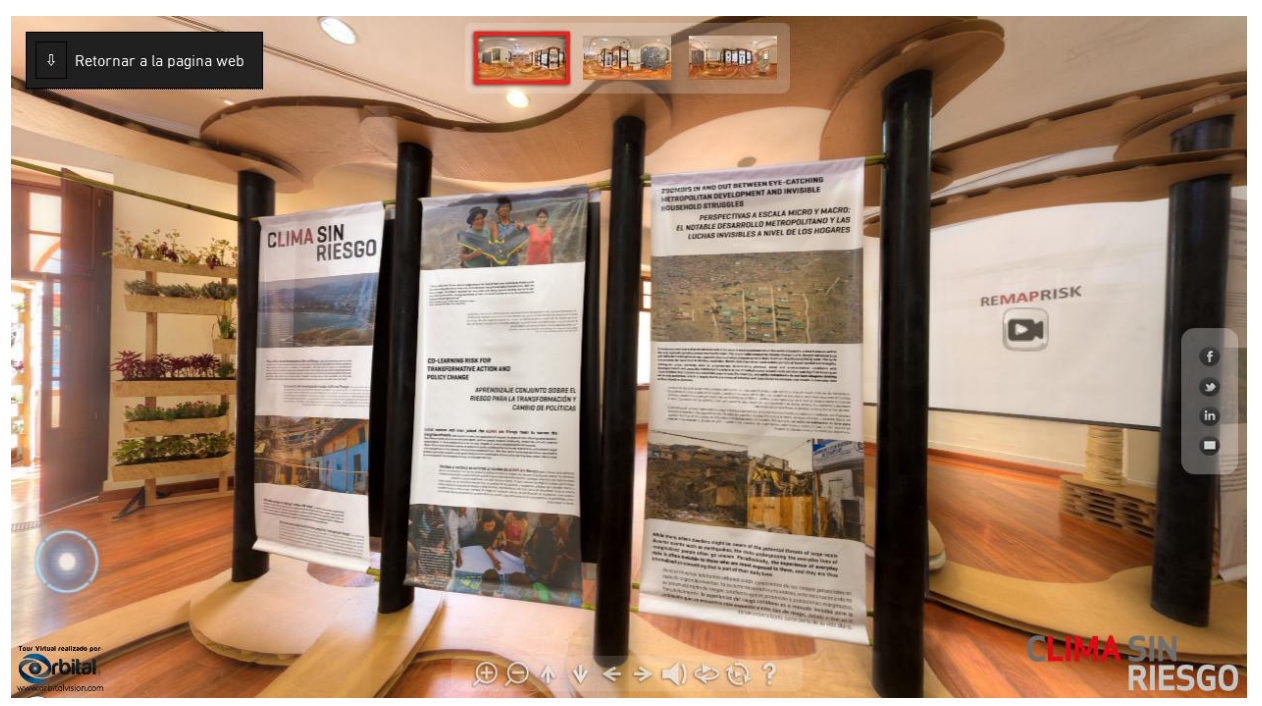

Figura 21: La exhibición virtual resume las metodologías y resultados del proyecto y es accesible desde el sitio web http://www.climasinriesgo.net 'Exhibición Virtual $360^{\circ}$ '.
Foto: cLIMA sin Riesgo 2016.

El legado de cLIMA sin Riesgo quedará en los múltiples espacios de aprendizaje colectivo generados y en la labor de los observatorios, las capacidades locales e institucionales forjadas y las alianzas con colegios profesionales, municipalidades, universidades, sociedad civil, expertos e instituciones científicas, aprovechando los espacios y procesos en curso para trabajar hacia un desarrollo urbano alternativo, justo y sin riesgos

\section{REFLEXIONES FINALES}

A primera vista, el análisis de ambos asentamientos proporciona una imagen desapacible. Mientras que los habitantes y organizaciones comunitarias de BA y JCM invierten implícita y explícitamente en la mitigación del riesgo, sus esfuerzos individuales y colectivos son insuficientes para abordar las causas subyacentes que crean y perpetúan las trampas de riesgo en ambas áreas. En Barrios Altos, la alta inseguridad de la tenencia, así como el deterioro constante y la falta de mantenimiento de las quintas, abren un espacio para usos mixtos y la especulación de la tierra, expulsando a residentes de largo arraigo en el área. En la periferia, la incertidumbre de los habitantes se refleja en la reproducción de prácticas fragmentadas de corto plazo que paradójicamente erosionan a lo largo del tiempo la capacidad de acción de los hogares y los entrampa en trayectorias de vida donde el riesgo se naturaliza como algo dado e inevitable. En ambos casos, vivir en riesgo se internaliza a lo largo del tiempo como el precio a pagar por un lugar en la ciudad.

Las encuestas en ambas áreas indican que los habitantes raramente articulan sus capacidades para invertir de manera colaborativa en mitigación, reducción y prevención de riesgo, sino más bien atacan las amenazas inmediatas en el momento en que se manifiestan. Si bien es difícil encontrar evidencia de inversiones sostenibles, los esfuerzos para desarrollar soluciones comunales usualmente no van acompañados de inversiones de mantenimiento. Como resultado, la infraestructura, espacios y facilidades comunales están con frecuencia en condiciones precarias y asociadas con mayores riesgos y problemas de mantenimiento que las áreas desarrolladas por los 
hogares individualmente. Sin embargo, las mejoras individuales y fragmentadas, como las que se realizan a nivel de hogar para asegurar el acceso al abastecimiento de servicios básicos en Barrios Altos, frecuentemente exacerban el riesgo de incendios, inundaciones y enfermedades relacionadas con el agua. Esto manifiesta la necesidad de que las políticas y los programas públicos apoyen intervenciones colectivas de prevención y reducción de riesgos a largo plazo.

El análisis de políticas públicas demuestra que Perú cuenta con ambiciosos planes y programas nacionales que aún no han sido suficientemente adaptados para abordar el proceso sistémico de la urbanización en riesgo (Diario Oficial El Peruano, 2011). Aunque desde el año 2011 se ha establecido un marco jurídico y procesal proactivo para pasar de la gestión del riesgo de desastres (GRD) a la prevención y reducción del riesgo de desastres (RRD), es necesario mejorar la capacidad de los gobiernos locales y descentralizar aún más los recursos para implementar efectivamente los presupuestos asignados y llegar a los grupos destinatarios de forma más eficaz. Los indicadores utilizados para medir la inversión pública en GRD tienen que ir más allá de cuantificar fondos destinados a obras de prevención y respuesta a emergencias para considerar los impactos deseados y no deseados de intervenciones públicas y privadas sobre la calidad del entorno construido y las condiciones de vida de los residentes locales. Más aún, es imprescindible involucrar a las comunidades locales en la producción y actualización de sistemas participativos de monitoreo y gestión del riesgo bajo condiciones de paridad que reconozcan sus experiencias y conocimiento, así como capacidades de acción. La producción de data y conocimiento desde la comunidad contribuye a mejorar el diseño y la orientación de los programas e inversiones estatales así como la evaluación de sus impactos efectivos.

Resumiendo, a pesar de los importantes esfuerzos emprendidos por los habitantes locales y las autoridades públicas para abordar la mitigación del riesgo de desastres, estos esfuerzos rara vez confluyen para reducir y prevenir la exacerbación de las trampas de riesgo urbano en las zonas donde viven las mujeres y los hombres más vulnerables. Sin embargo, la reproducción de la urbanización en riesgo no es un proceso inevitable y sus raíces pueden ser abordadas actuando sobre varias áreas claves:

En primer lugar, la construcción de los riesgos cotidianos ocurre de manera incremental e invisible. Varias intervenciones en el entorno construido - tanto formales como informales - a menudo crean ciclos viciosos de acumulación de riesgo que son exacerbados por la incertidumbre climática y pueden resultar en eventos de desastre. Por lo tanto, las políticas y los programas deben ir acompañados de substanciales esfuerzos locales de monitoreo, como los establecidos a través de observatorios urbanos o plataformas de aprendizaje-acción, para visibilizar los efectos incrementales sobre la calidad de vida de las personas. Al mismo tiempo, es fundamental reconocer que los hogares atrapados en trampas de riesgo requieren un apoyo estratégico, vigoroso y concertado.

En segundo lugar, los niveles de vulnerabilidad y riesgo suelen ser heterogéneos aun entre aquellos que viven en una misma área. Factores como el género, la relación de dependencia socioeconómica, el nivel de ingresos, la localización y la historia del asentamiento explican la susceptibilidad de los hogares a quedar entrampados en trayectorias de riesgo y forzados a internalizar o externalizar los posibles efectos de fenómenos peligrosos. Sin embargo, las inversiones públicas fallan con frecuencia en priorizar efectivamente a las áreas y grupos sociales más vulnerables. Esto requiere esfuerzos para contextualizar el diseño e implementación de programas en base a las características específicas de los beneficiarios, identificando así quiénes son vulnerables, a qué tipo de riesgos son vulnerables, dónde, por qué, y qué capacidad tienen para actuar.

En tercer lugar, la evaluación de las políticas gubernamentales muestra que existen planes y programas diseñados para la GRD a nivel nacional, regional y local, junto con un presupuesto creciente y un marco legal y procesal proactivo para pasar de la mitigación de riesgos a su reducción y prevención. Sin embargo, la gran brecha entre la asignación presupuestaria a las autoridades locales y las inversiones específicas realizadas a escala local, resalta la necesidad de fortalecer las capacidades de los gobiernos locales para utilizar los recursos financieros existentes, aunque sean escasos. Las inversiones públicas deben ser evaluadas en relación con sus impactos directos e indirectos sobre la reducción y prevención del riesgo a corto, mediano y largo plazo, para abordar las causas estructurales subyacentes de la vulnerabilidad.

En cuarto lugar, los encargados de la formulación de políticas de GRD deben diseñar y evaluar sus inversiones en relación con otras inversiones que ya están en curso, como las que son realizadas por los habitantes locales, que aunque sean pequeñas, se acumularán gradualmente. También deben evaluar los impactos reales de las intervenciones que aumentan el riesgo, como las vías que 
promueven la ocupación de áreas peligrosas, así como las consecuencias de no invertir en mejoras que puedan reducir la vulnerabilidad de las personas a los riesgos cotidianos. Los habitantes locales tienen una enorme capacidad para gestionar e invertir en la construcción de sus vidas en la ciudad. Sin embargo, las soluciones y políticas individuales que promueven intervenciones individualizadas no responden a las causas estructurales subyacentes de los ciclos de riesgo. Esto requiere más esfuerzos colectivos y participativos que incluyan el conocimiento y los recursos de los ciudadanos y actores públicos para consolidar beneficios a largo plazo para grupos más amplios de mujeres y hombres que viven en riesgo.

Por último, es importante considerar las sinergias en los procedimientos para la reducción del riesgo de desastres, el cambio climático, la vulnerabilidad a los riesgos cotidianos y a los desastres episódicos a pequeña escala, al conceptualizar e implementar procesos de desarrollo alternativo. La experiencia de cLIMA sin Riesgo señala que la interrupción de círculos viciosos de acumulación de riesgo depende en gran medida de la construcción de sinergias entre los esfuerzos orientados a la reducción del riesgo de desastres, el cambio climático y la vulnerabilidad, pero bajo una perspectiva más amplia que vincule estos esfuerzos a la búsqueda de procesos de desarrollo urbano más justos y sustentables. Sin una perspectiva a largo plazo sobre los procesos que producen y reproducen trampas de riesgo urbano, es probable que las respuestas estatales continúen enfocándose en desastres de gran escala, perdiendo de vista la violencia invisible y lenta de los riesgos cotidianos y desastres episódicos que afectan a un porcentaje considerable de mujeres y hombres empobrecidos.

\section{REFERENCIAS}

Ahmed, S., Castellani, L., Hoyos Jiménez, J., Langdown, I., Punsri, P., Sit, F., et al. (2015). José Carlos Mariátegui: Más allá del riesgo: una gestión corresponsable del borde de la ciudad [Video Online]. MSc Environment \& Sustainable Development / Practice Module ES3. The Bartlett Development Planning Unit (DPU), University College London (UCL). Recuperado el 16 de Febrero 2017 del sitio web: https://youtu.be/QKjAS5nDLuw

Allen, A. (2015). The risk wheel: Understanding the universe of risk coping and mitigating practices deployed by state agencies and ordinary citizens in the periphery of Lima. MSc Environment \& Sustainable Development / Practice Module ES3. The Bartlett Development Planning Unit (DPU), University College London (UCL).

Allen, A., Belkow, T., de los Ríos, S., Escalante C., Lambert, R., Miranda, L., et al. (2015). Perspectivas para la Acción $\mathrm{N}^{\circ}$ 1: Riesgo urbano: En busca de nuevas miradas. cLIMA sin Riesgo. Londres \& Lima: The Bartlett Development Planning Unit (DPU), University College London (UCL). Recuperado el 16 de Febrero 2017 del sitio web: http://www.climasinriesgo.net/wp-content/uploads/2015/o7/ FINAL_Policy-Brief-1_22Oct2015_SP_rp.pdf

Allen, A., Wesely, J., Zilbert, L., en colaboración con Belkow T., Ferro V.; Langdown I.; Poblet, T. \& Samanamu, A. (2016). Perspectivas para la Acción $N^{\circ}$ 3: Capacidades e inversiones en la gestión de asentamientos y el riesgo urbano. cLIMA sin Riesgo. Londres \& Lima: The Bartlett Development Planning Unit (DPU), University College London (UCL). Recuperado el 16 de Febrero 2017 del sitio web:http://www.climasinriesgo.net/wp-content/uploads/2016/11/N3-SPN-website-.pdf

Allen, A., Arango, J. L., Belkow, T., Escalante, C., Kamiya, M., Miranda, L., et al. (2017a). Perspectivas para la Acción $\mathrm{N}^{\circ} 4$ : Interrumpiendo trampas de riesgo urbano: Rutas para la acción. cLIMA sin Riesgo. Londres \& Lima: The Bartlett Development Planning Unit (DPU), University College London (UCL).

Allen, A., Belkow, T., Benitez, F., Escalante, C., Lasso, S., Miranda, L., et al. (2017b). Boletín $N^{\circ}$ 5: Interrumpiendo trampas de riesgo urbano: Construyendo caminos y acciones transformativas. cLIMA sin Riesgo. Londres \& Lima: The Bartlett Development Planning Unit (DPU), University College London (UCL).

Bardossy, A.; Jochen, S. \& Chamorro, A. (2011). Modelamiento del Clima y Balance Hídrico de Lima. Stuttgart: Proyecto LiWa - IWS - Universidad de Stuttgart.

Bielich C. \& Alegre M., (2015). Vulnerabilidad Urbana: Evaluando los nuevos factores de riesgo en Lima Metropolitana. Oxfam América, Lima, 10-25. 
Bull-Kamanga, L.; Diagne, K.; Lavell, A.; Leon, A.; Lerise, F.; MacGregor, H.; Maskrey, A.;

Meshack, M.; Pelling, M.; Reid, H.; Satterthwaite, D.; Songsore, J.; Westgate, K. \& Yitambe, A. (2003). From everyday hazards to disasters: the accumulation of risk in urban areas. Environment and Urbanization, 15(1), 193-204. Recuperado el 28 de Enero 2017 del sitio web:

http://eau.sagepub.com/cgi/doi/10.1177/095624780301500109

CRID (Centro Regional de Información sobre Desastres para América Latina y el Caribe). (20o8). Vocabulario controlado sobre desastres.San José, Costa Rica: CRID. Recuperado el 10 de Diciembre 2016 del sitio web: http://www.cridlac.org/vcd/files/page422.html

Diario la República. (2017). Río Huaycoloro se desborda, inunda SJL \& llega al Rímac. 01.02.2017. Recuperado el 10 de Febrero 2017 del sitio web: http://larepublica.pe/impresa/ sociedad/844631-rio-huaycoloro-se-desborda-inunda-sjl-y-llega-al-rimac

INEI. (2015). Nota de Prensa INEI: 9 millones 752 mil Limeños celebran 480 años de fundación de la ciudad de Lima. 17.012015. Recuperado el 10 de Diciembre 2016 del sitio web: http://www.inei.gob.pe/prensa/ noticias/9-millones-752-millimenos-celebran-48o-anos-defundacionde-la-ciudad-de-lima-8173/

Lambert, R. \& Allen, A. (2016). Participatory Mapping to Disrupt Unjust Urban Trajectories in Lima. En Imperatore, P. (Ed.), Geospatial Technology - Environmental and Social Applications (pp.143-165). Rijeka: InTech. Recuperado el 10 de Diciembre 2016 del sitio web: http://www. intechopen.com/books/geospatial-technology-environmental-and-social-applications/ participatory-mapping-to-disrupt-unjust-urban-trajectories-in-lima

Lambert, R. C., Rickles, P., \& Espinoza, F. (2016a). José Carlos Mariátegui: Riesgos Cotidianos y Desastres episódicos. Mapas Parlantes. Londres \& Lima: The Bartlett Development Planning Unit (DPU), University College London (UCL). Recuperado el 16 de Febrero 2017 del sitio web: http://arcg.is/1FkV5MD.

Lambert, R. C., Rickles, P., Belkow, T., \& Woo, M. I. (2016b). Barrios Altos: Riesgos Cotidianos y Desastres episódicos. Mapas Parlantes. Londres \& Lima: The Bartlett Development Planning Unit (DPU), University College London (UCL). Recuperado el 16 de Febrero 2017 del sitio web: http://arcg.is/1FkV5MD.

Lavell, A., Mansilla, E., Smith, D., Brenes, A., Romano, L. \& Somarriba, H. (2003). La gestión local del riesgo: nociones y precisiones en torno al concepto y la práctica. Guatemala \& Ginebra: Centro de Coordinación para la Prevención de los Desastres Naturales en América Central (CEPREDENAC), Programa de Naciones Unidas para el Desarrollo (PNUD).

Diario Oficial El Peruano. (2011). Ley 29664, Creación del Sistema Nacional de Gestión del Riesgo de Desastres (SINAGERD). 18.02.2011.

Miranda, L., Torres, R., \& Arana, E., (2015). Lima, vulnerabilidad climática y escenarios al 2040. Foro Ciudades para la Vida, Documento de trabajo.

MML (Municipalidad Metropolitana de Lima). (2012), Proyecto "Estrategia de Adaptación al CC de la $M M L ”$. Foro Ciudades para la Vida y AVINA, Lima.

MML (Municipalidad Metropolitana de Lima). (2014). Plan Metropolitano de Desarrollo Urbano Lima y Callao 2035 (PLAM 2035). Lima: Instituto Metropolitano de Planificación.

MML (Municipalidad Metropolitana de Lima). (2015). Noticias: Más de 3 mil personas se beneficiarán con escaleras que construye MML. 20.06.2015. Recuperado el 1o de Febrero 2017 del sitio web: http://www.munlima.gob.pe/noticias/1-noticias/m\% $3 \%$ A1s-de-3-milpersonasse- beneficiar\%$\mathrm{C}_{3} \%$ Ain-conescalerasque-construye-mml

de los Rios Bernandini, S. (2006). Cifras de Tugurización en Viviendas en Lima Metropolitana.

Lima: Centro de Investigación, Documentación y Asesoría Poblacional, CIDAP.

Recuperado el 12 de Enero 2017 del sitio web: https://es.scribd.com/doc/62980927/

Cifras-de-Tugurizacion-en-Viviendas-en-Lima-Metropolitana\#scribd 
de los Rios Bernandini, S. (2009). Centro Histórico de Lima: Patrimonio Vivo y Auténtico en Riesgo. Lima: Centro de Investigación, Documentación y Asesoría Poblacional, CIDAP. Recuperado el 12 de Enero 2017 del sitio web: https://es.scribd.com/doc/63145083/ Informe-Dia-Internacional-de-los-Monumentos-y-Sitios

SGRD (Secretaría de Gestión del Riesgo de Desastres, PCM). (2015). Documento de Línea de Base del Plan Nacional de Gestión del Riesgo de Desastres PLANAGERD 2014-2021. Lima: PCM.

UNISDR. (2009). Terminología sobre Reducción de Riesgo, Ginebra: UNISDR. Recuperado el 8 de Marzo 2015 del sitio web http://www.unisdr.org/files/7817_UNISDRTerminologySpanish.pdf

UNISDR. (2011). Tendencias de Riesgos de desastres extendidos. Informe de Evaluación Global sobre la Reducción del Riesgo de Desastres 2011: Revelar el riesgo, Redefiniendo el Desarrollo. Ginebra: UNISDR.

UNISDR. (2015). El GAR de bolsillo 2015. Hacia el desarrollo sostenible: El futuro de la gestión del riesgo de desastres. Ginebra: UNISDR. Recuperado el 10 de Diciembre 2016 del sitio web: http://www.preventionweb.net/english/hyogo/gar/2015/en/gar-pdf/GAR15_Pocket_ES.pdf

Vásquez Huamán, E., (2012). El Perú de los pobres no visibles para el Estado: la inclusión social pendiente a julio del 2012. Documento de Discusión. Centro de Investigaciones de la Universidad Pacífico.

Wisner, B., Blaikie, P. T. \& Cannon, D., I. (2004). At Risk: Natural hazards, people's vulnerability and disasters. People's vulnerability and disasters (2a ed.). Nueva York: Routledge.

Zilbert Soto, L., (2008). Los desastres ¿problemas no resueltos del desarrollo? Territorio y Naturaleza. Desarrollo en Armonía. Serie: Perú Hoy, No.14, Diciembre. 